\title{
Two-Phase Flow Model for Numerical Investigation of Impact of Water Retention on Shale Gas Production
}

\author{
Ershe Xu, ${ }^{1,2,3}$ Lingjie Yu, ${ }^{1,2,3}$ Ming Fan, ${ }^{1,2,3}$ Tianyu Chen $\triangle{ }^{4}$ Zhejun Pan ${ }^{\circ},{ }^{5}$ \\ Yuling Tan $\mathbb{D}^{6},{ }^{6,7}$ and Guanglei Cui $\mathbb{1}^{4}$ \\ ${ }^{1}$ Wuxi Research Institute of Petroleum Geology, SINOPEC, Wuxi 214126, China \\ ${ }^{2}$ SINOPEC Key Laboratory of Petroleum Accumulation Mechanism, Wuxi 214126, China \\ ${ }^{3}$ State Key Laboratory of Shale Oil and Gas Enrichment Mechanisms and Effective Development, Wuxi 214126, China \\ ${ }^{4}$ Key Laboratory of Ministry of Education on Safe Mining of Deep Metal Mines, Northeastern University, Shenyang 110004, China \\ ${ }^{5}$ Key Laboratory of Continental Shale Hydrocarbon Accumulation and Efficient Development, Ministry of Education, \\ Northeast Petroleum University, Daqing, Heilongjiang 163318, China \\ ${ }^{6}$ Department of Engineering Mechanics, Shijiazhuang Tiedao University, Shijiazhuang 050043, China \\ ${ }^{7}$ Hebei Key Laboratory of Mechanics of Intelligent Materials and Structures, Shijiazhuang Tiedao University, \\ Shijiazhuang 050043, China
}

Correspondence should be addressed to Guanglei Cui; cuiguanglei@mail.neu.edu.cn

Received 29 August 2021; Revised 11 November 2021; Accepted 12 November 2021; Published 20 December 2021

Academic Editor: Tianran Ma

Copyright (c) 2021 Ershe Xu et al. This is an open access article distributed under the Creative Commons Attribution License, which permits unrestricted use, distribution, and reproduction in any medium, provided the original work is properly cited.

In this work, a triple-porosity, two-phase flow model was established to fill the knowledge gap of previous models focusing on gas production characteristics while ignoring the impacts of water injection. The proposed model considers the water flow in the fracture systems and clay minerals and the gas flow in the organic matter, inorganic pore, and fracture systems. The proposed model is solved using a finite element approach with COMSOL Multiphysics (Version 5.6) and verified with field data. Then, the evolutions of the intrinsic and relative permeabilities during water injection and gas production are examined. Furthermore, the impacts of water injection time and pressure are investigated. Good verification results are obtained; the goodness-of-fit value is 0.92 , indicating that the proposed model can replicate both the water stimulation and the gas production stages. The relative gas permeability declines during water injection but recovers in the gas depletion stage. Furthermore, the intrinsic permeability increases during the water injection stage but decreases during the gas production stage. A higher water injection pressure and longer injection time would enlarge the intrinsic permeability, thus improving flow capacity. However, it would reduce gas relative permeability, thereby hindering gas flow. The shale gas production characteristic is controlled by the two abovementioned competing mechanisms. There exists a perfect combination of water injection pressure and injection time for achieving the maximum profitability of a shale gas well. This work can give a better understanding of the two-phase flow process in shale reservoirs and shed light on the field application of hydraulic fracturing.

\section{Introduction}

Compared with other fossil fuels, shale gas plays an important role in the global energy mix with the exhaustion of conventional reservoirs $[1,2]$. Owing to the extremely low permeability (nanodarcies, $10^{-21} \mathrm{~m}^{2}$ ) and porosity (less than $5 \%$ ) of shale gas [3], highly effective reservoir stimulation technologies are vital for the successful exploitation of shale gas reservoirs [4]. Hydraulic fracturing (HF), wherein large volumes of water are injected into shale reservoirs to induce gas production, is a mainstream method of stimulation (Figure 1(a)). Injected water flows into the hydraulic fractures and enters the shale matrix, thus occupying the gas flow channels and impairing the gas flowback process [5] (Figure 1(b)). Besides the injected water, abundant reserves of connate water are present in shale gas reservoirs [6,7]; this is adsorbed on the surface of inorganic matter (clays) $[8,9]$ or trapped by capillary pressure in small inorganic pores $[5,10]$. In general, connate water is initially immobile. 


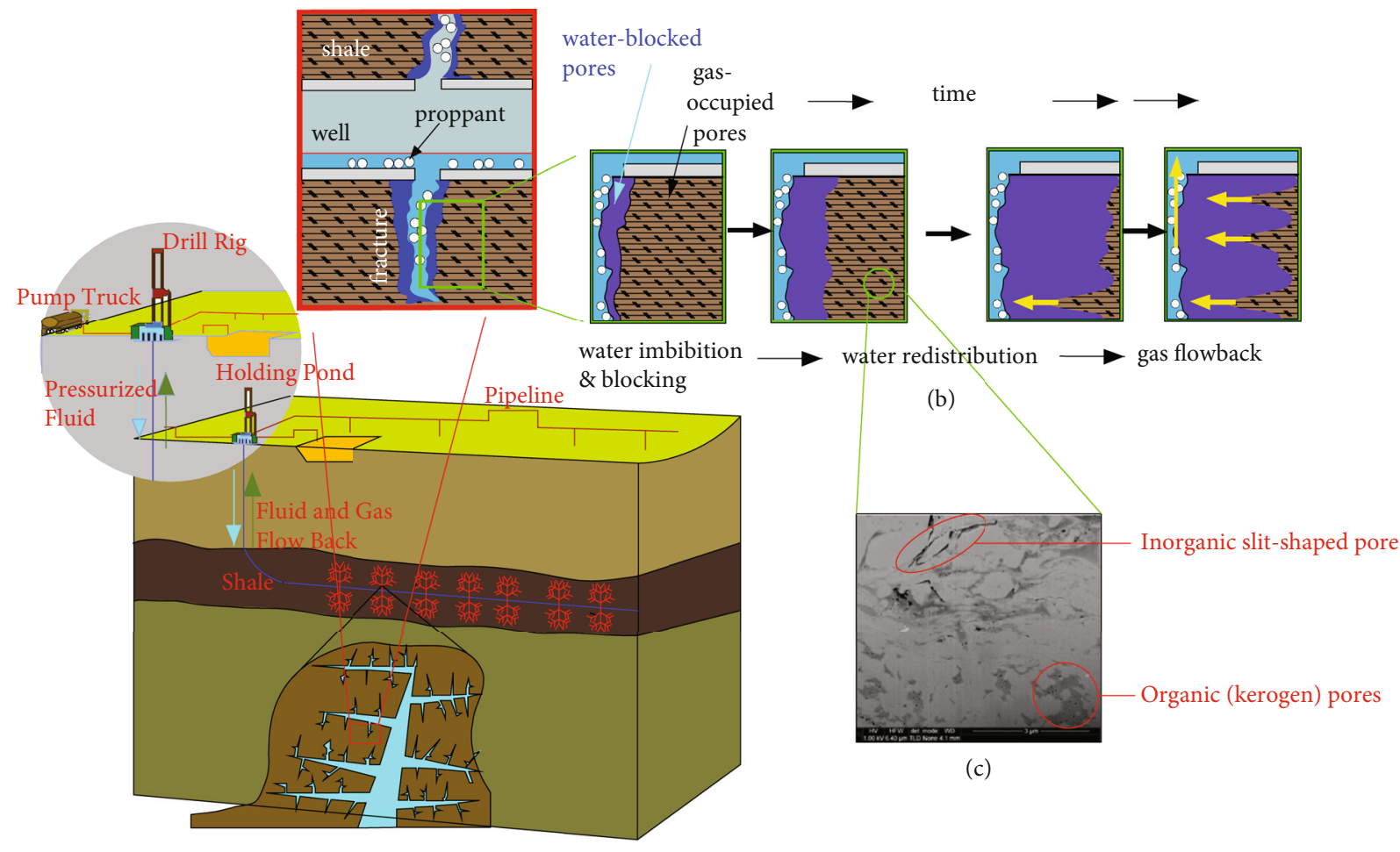

(a)

FIgURE 1: (a) Schematic illustration of shale gas HF. (b) Water imbibition process in a shale reservoir. (c) SEM image of the shale matrix.

However, during the water injection process, part of the penetrating water becomes residual water in the inorganic matrix, since it is filled to normal irreducible water saturation $[11,12]$. In conclusion, both injected water and connate water can significantly impact gas production characteristics [13], yet most gas production models only consider the influence of gas pressure and effective stress or connate water [14]; there is no comprehensive investigation of the impacts of injected water.

Injected hydraulic water dramatically influences gas diffusivity and permeability $[15,16]$, thereby hindering gas transport in shale. According to experimental results for the Svalbard Shale, moisture content strongly decreases Ar and $\mathrm{CO}_{2}$ permeability [17]. Increasing water saturation leads to an exponential decline in apparent effective He permeability; at a water saturation of approximately $30 \%$, He permeability decreased strongly [18]. Further, the permeability of crushed shale samples exhibited exponential decline when saturated with water [19]. In addition, retained water can occupy void spaces and adsorption sites that were initially originally available for gas storage through two mechanisms [20]: (i) a part of void space would be occupied by injected water, directly decreasing the free gas content in shale [21, 22]. (ii) Moreover, pore surface sites originally intended for methane adsorption are partially occupied by water molecules through competitive adsorption, since condensed water is blocking the pore throat, resulting in a decline in gas adsorption capacity [21, 23-25].

The two-phase flow process during shale gas production has been widely investigated analytically and semianalytically with the influence of complexity and half-length of hydraulic fracture $[26,27]$, increased permeability, and frac- ture conductivity in stimulated reservoir volume (SRV) [28, 29] considered. In Clarkson and Williams-Kovacs' work, the short-term flowback data was adopted to characterize water and gas production characteristics and flowing pressure [26]. In the later work, Williams-Kovacs and Clarkson [28] proposed a data-driven pseudoanalytical model in which the two-phase flowback process was investigated and the impacts of key frac properties were analyzed. However, the complex coupling mechanisms between reservoir deformation and gas-water two-phase flow are typically ignored in these previous approaches [30]. By countering this problem, numerical reservoir models are widely used to predict production [2, 14], improve profitability [31], and understand potential hazards [32]. Cao et al. [33] proposed a multiscale, multiphase model for gas-water two-phase flow within shale reservoirs. Based on an evaluation of shale gas recovery, the model can quantitatively differentiate these properties of fractured water. Later, a multidomain unstimulated reservoir volume (USRV) and stimulated reservoir volume (SRV), multiphysics model was proposed by Cui et al. [14] to represent two-phase flow within a heterogeneous shale gas reservoir. In $\mathrm{Li}$ et al.'s work $[34,35]$, a three-component solid system including organic kerogen, inorganic matrix, and hydraulic fracture (HF) was specified to characterize twophase flow during the gas production stage. The dual-porosity, dual-permeability media was adapted to the first two components with a $1 \mathrm{D}$ cracked medium referred to as the last for simplification. Different properties in the so-called stimulated reservoir domain (SRD) and unstimulated reservoir domain (SRD) were assumed to simulate the influence of $\mathrm{HF}$ in the near-HF matrix. 
As mentioned above, current gas production models are mostly focused on gas flow characteristics and ignore the impacts of the injection of hydraulic water. In other words, only the gas production stage is replicated in the simulation work, and the water injection process is seldom studied. In such approaches, the impacts of water injection pressure and injection time are not fully understood. To address these shortcomings, this study proposes a coupled two-phase flow model to comprehensively examine the effect of injected water on reservoir production. A group of partial differential equations governing the multiscale, two-phase flow in a shale gas reservoir is proposed, and both intrinsic and relative permeability evolutions are considered. The proposed model is elucidated via numerical simulations and sensitivity analyses and verified with field data.

This paper is organized as follows: the conceptual model and mathematical model are presented in Sections 2 and 3, respectively. Then, model verification is conducted in Section 4, and the results and discussion are shown in Section 5. Finally, the conclusions are explained in Section 6.

\section{Conceptual Model}

2.1. Triple-Porosity Model. A field emission scanning electron microscopy (FESEM) image (Figure 1(c)) [36-40] is selected to represent highly heterogeneous properties of shale matrix, such as mineral constituents, pore structure, and gas storage term. Based on these observations, a tripleporosity model was established in this study to probe the effect of hydraulic water and connate water on shale gas production characteristics. In this triple-porosity model, the shale reservoir is divided into the fracture system, inorganic matrix, and organic matter [41]. Free gas exists in the fracture system and inorganic matrix, whereas absorbed gas is present in the organic matter [42]. The hydraulic fluid enters the fracture system and inorganic matrix system, while connate water exists in the inorganic matrix and organic matter, impacting the gas storage amount.

\subsection{Water Injection Process}

(a) Initial equilibrium state and pressure rise stage

As shown in Figure 2(a), before HF, the water saturation is relatively low. As the injection process continues, the water injection volume increases linearly with time, and the water pressure in the wellbore rises continuously with continuous water injection. Water percolation in shale reservoir fractures can be described by Darcy's law [43]. When the water pressure reaches the fracture pressure, the shale reservoir is in a critical state, which manifests externally as hydraulic fractures.

\section{(b) HF stage}

Under the combined action of in situ stress and highpressure water, the radial stress on the inner surface of the fracture hole is expressed as compressive stress and the tangential stress is expressed as tensile stress [44]. Because the compressive strength is much greater than the tensile strength, the newly generated fractures in the shale reservoir are mostly initiated by tensile failure [45]. The fracture initiation and propagation mechanisms of $\mathrm{HF}$ are generally described by fracture mechanics failure criteria: the tensile strength criterion and the Mohr-Coulomb criterion [46]. As shown in Figure 2(b), after HF is initiated, the injection water flows into the main fracture network, and generally the Darcy equation is applied.

\section{(c) Water imbibition stage}

The water environment is shaped under the water pressure after the fracture penetrates, and the water imbibition process can be divided into three stages. First, water enters the fracture system (Darcy's law). Then, it diffuses into the inorganic matrix. In this work, only clay minerals are assumed to be highly hygroscopic. In the last stage, the water diffuses into the organic matter through a competitive adsorption behavior. When the injection water diffuses into the shale matrix from the hydraulic or natural fractures, as shown in Figure 2(c), the gas relative permeability of the shale reservoir changes impacting the gas flow characteristics.

\section{(d) Final equilibrium state}

During the fracturing process, a large amount of slick water is pumped into the reservoir for several days. A technique called soak-back was recently developed to boost production after HF; it sets a well shut-in period (soaking time) to soak the fracture fluids and thus increase productivity. During these two processes, the hydraulic fluid continues to diffuse until a new equilibrium state is reached. However, a new state may never be achieved, as thousands of years are needed [2].

\subsection{Gas Production Process}

(a) Bubble flow

The water flowback and gas production processes can be roughly split into four stages as shown in Figure 3. In the first stage (Figure 3(a)), water in the horizontal well and hydraulic fracture fluid flow back together with a small amount of free gas. This part is known as bubble flow.

(b) Water-dominant two-phase flow

In the later stage (Figure 3(b)), the water in the inorganic matrix is depleted, since the water saturation between the hydraulic fracture and inorganic matrix is different. In this stage, some free gas in the inorganic matrix flows back because of the pressure difference. In this stage, the water flow plays the dominant role. The water saturation is higher than the gas saturation, leading to a significant larger water relative permeability.

(c) Gas-dominant two-phase flow

In the middle and later stages of production (Figure 3(c)), the residual water on the fracture surfaces is 


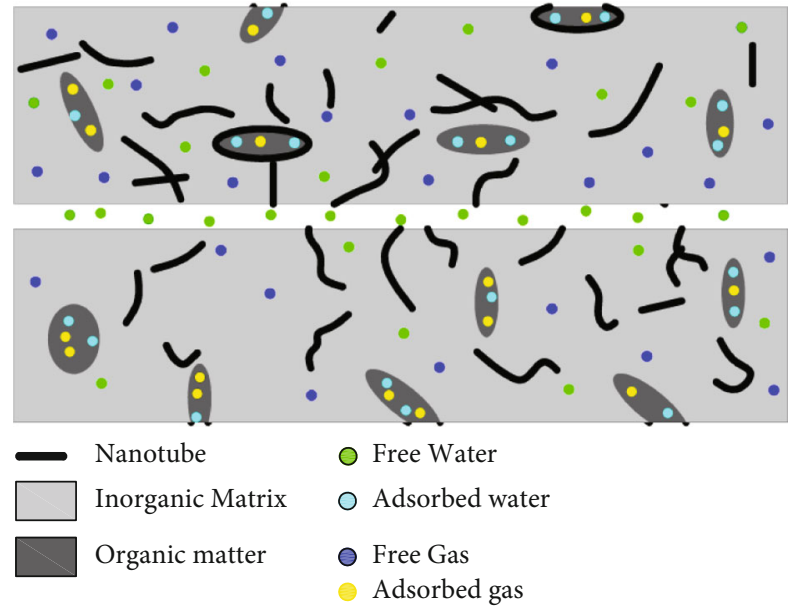

(a)
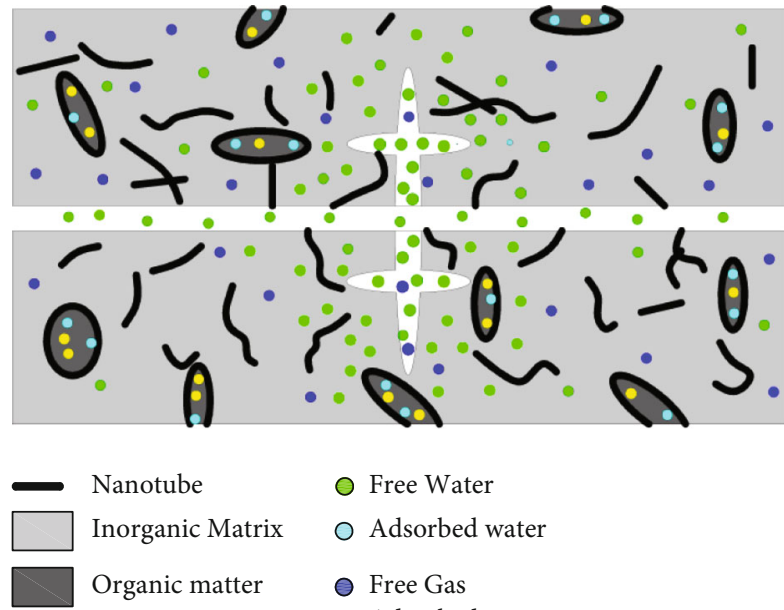

\begin{abstract}
Nanotube
Inorganic Matrix $\bigcirc$ Adsorbed water

Organic matter $\bigcirc$ Free Gas

Adsorbed gas
\end{abstract}

(c)

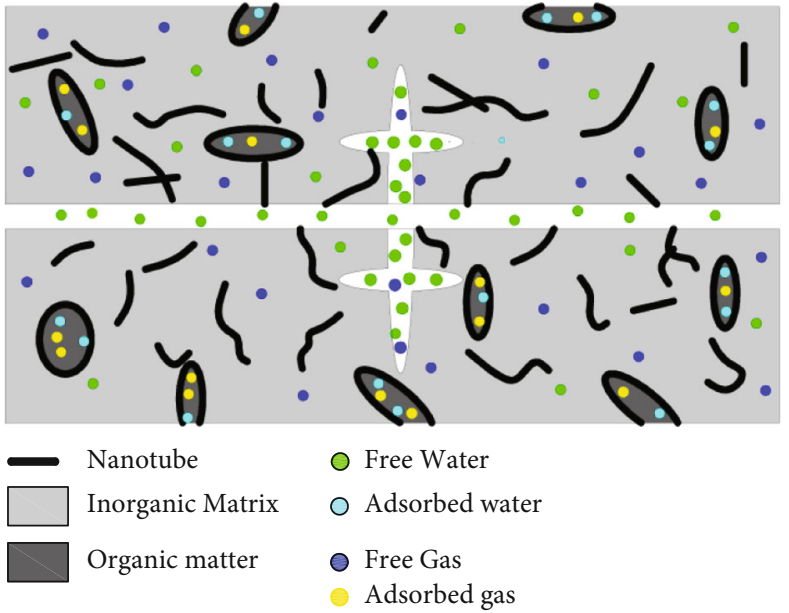

(b)
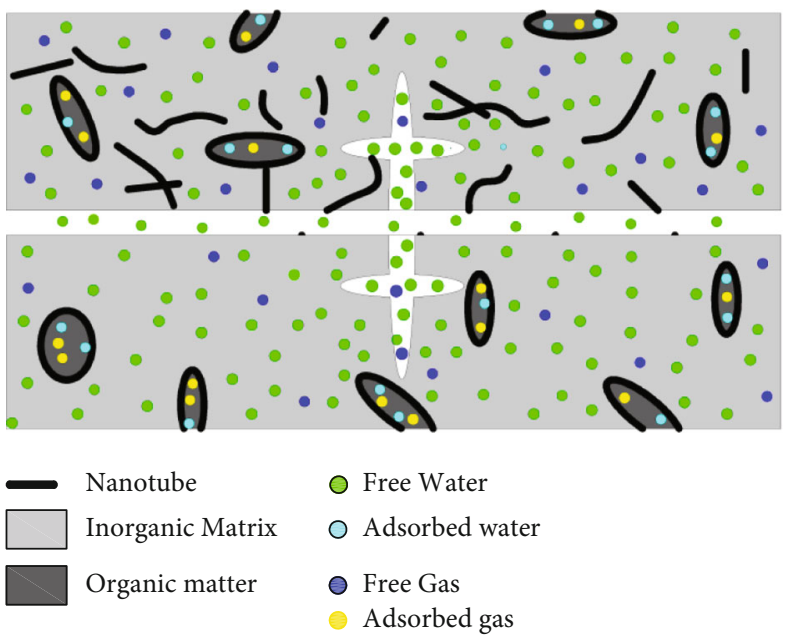

(d)

FIGURE 2: Schematic illustration of the water injection process: (a) initial and pressure rise stages, (b) HF stage, (c) water imbibition stage, and (d) final stage.

extracted through moisture transport. In the meantime, the fracture permeability is improved, since the gas flow channels in the fractures are widened by the evaporation of the water film, which also increases the gas output. Additionally, the adsorbed gas in the organic matter begins to diffuse because of the gas concentration gradient.

\section{(d) Final equilibrium state}

In the final state (Figure 3(d)), all the water and gas molecules are depleted, and a new equilibrium state is achieved. However, this state is difficult to achieve, as more than 3,000 years are needed to attain full equilibrium, as shown in a previous work [2].

\subsection{Competitive Adsorption between Gas and Water. Shale} gas adsorption under dry conditions plays a vital role in gas in place (GIP) estimation [47, 48]. Although a few studies have been conducted on methane adsorption in moisture-equilibrated shale [23, 49], the impact of water content has not been fully studied.
Figure 4 illustrates the microscopic differences between saturated shale (low/high moisture content) and dry shale. The adsorption sites in the shale matrix-the organic structure surfaces and the clay mineral surfaces-are fully occupied under dry conditions. However, these characteristics are quite different under moist conditions: (i) functional groups containing oxygen and nitrogen atoms are of stronger water absorption capacity and (ii) water molecules are easily adsorbed on clay minerals. Both conditions greatly reduce the shale gas adsorption capacity. Hence, a shale gas reservoir can achieve maximum adsorption capacity under dry conditions.

\section{Mathematical Model}

3.1. Gas-Water Two-Phase Flow in the Fracture System. The mass conservation equation of gas-water two-phase flow in a fracture system is given as [50]

$$
\frac{\partial m_{f a}}{\partial t}+\nabla \cdot J_{f a}=Q_{f a}
$$



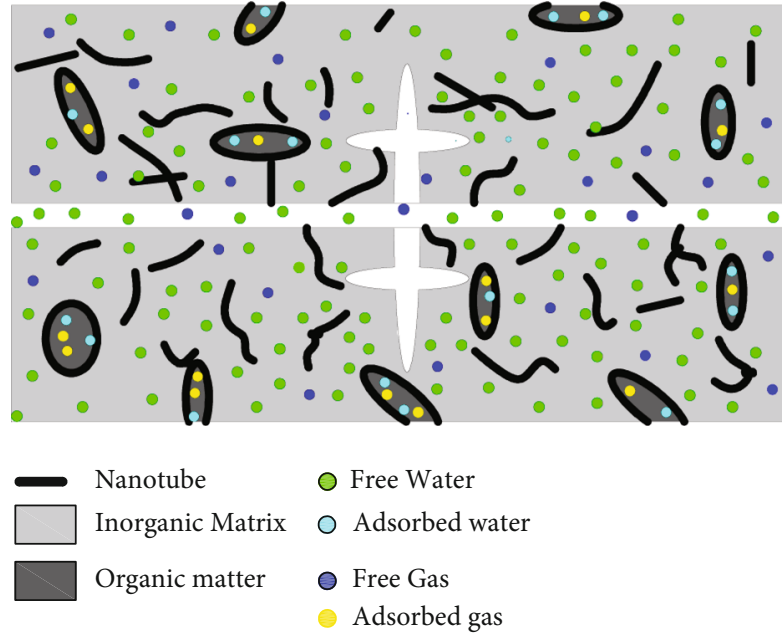

(a)
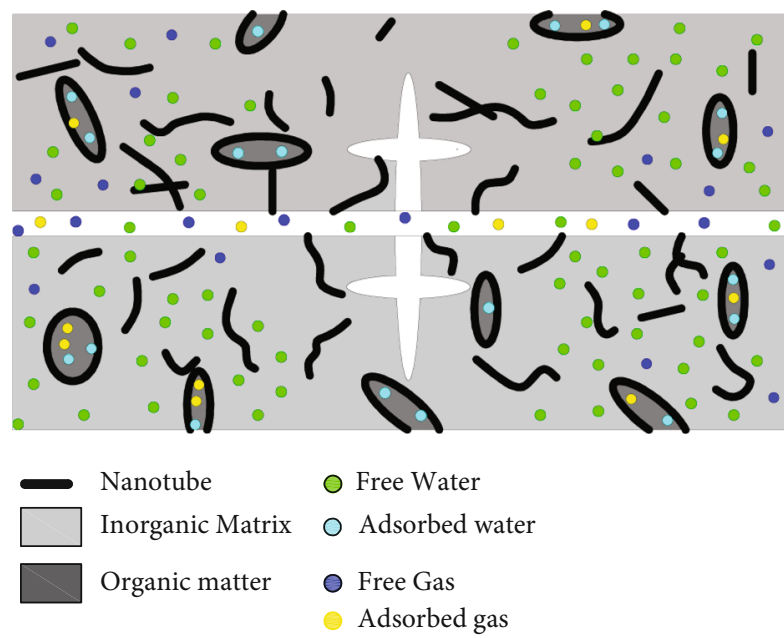

(c)
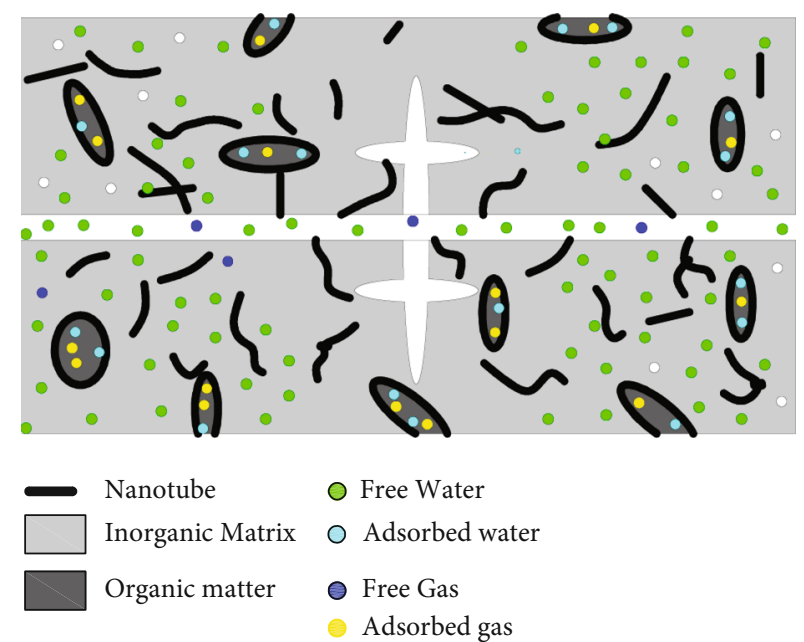

(b)
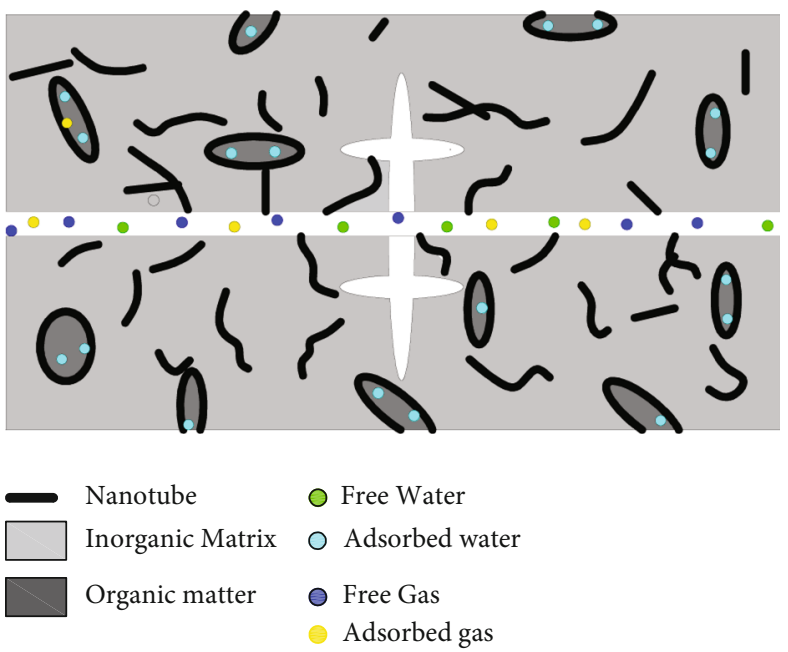

(d)

FIGURE 3: Schematic illustration of the gas production process: (a) bubble flow, (b) water-dominant two-phase flow, (c) gas-dominant two-phase flow, and (d) the new equilibrium state.

where subscript $\alpha$ refers to either water $(w)$ or gas $(g)$, subscript $f$ denotes the fracture system, and $Q_{f \alpha}$ refers to the flow source or sink. With the consideration of gravity, the mass flux $J_{f \alpha}$ of the fluid can be calculated as [51]

$$
J_{f a}=-\rho_{f a} \frac{k_{f} k_{f r a}}{\mu_{a}}\left(\nabla p_{f a}+\rho_{f a} \mathbf{g}\right)
$$

where $k_{f}$ and $k_{f r a}$ are the intrinsic and relative permeabilities, respectively, of the fracture system, $p_{a}$ represents the pore pressure, $\mu_{\alpha}$ represents the viscosity, and $\mathbf{g}$ represents the acceleration due to gravity.

The water mass $\left(m_{w f}\right)$ only contains free phase and is calculated as [52]

$$
m_{w f}=s_{w f} \rho_{w f} \phi_{f}+Q_{w f},
$$

where $s_{w f}$ refers to the water saturation, $\rho_{w f}$ represents the water density, $\varphi_{f}$ refers to the porosity, and $Q_{w f}$ refers to the water source term.

The gas mass $\left(m_{g f}\right)$ is composed of free gas and mass resources provided by the inorganic pore system [53].

$$
m_{g f}=s_{g f} \rho_{g f} \phi_{f}+Q_{\mathrm{in} 2 f},
$$

where $s_{g f}$ and $\rho_{g f}$ represent the gas saturation and gas density, respectively.

The gas mass transfer term is proportional to the gas content difference between the fracture and inorganic matrix systems:

$$
Q_{\mathrm{in} 2 f}=\frac{\omega_{\text {in }} k_{\text {apin }}}{\mu} \rho_{\text {ing }}\left(p_{f}-p_{\text {in }}\right),
$$

where $\omega_{\text {in }}$ is the shape factor. 


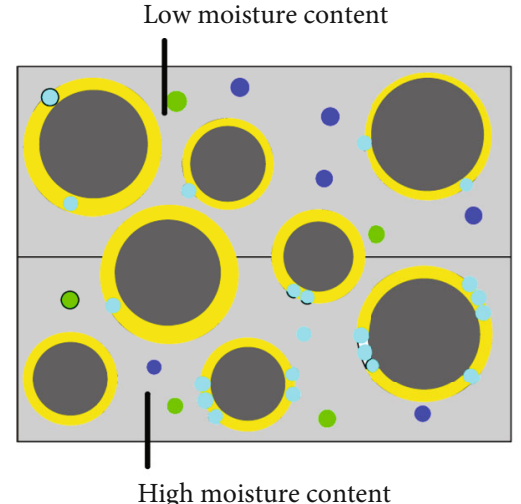

(a)

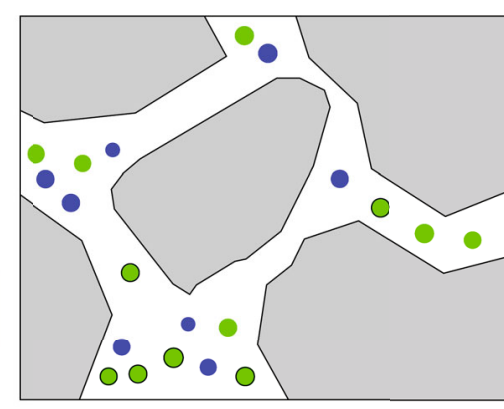

(b)

\begin{tabular}{|c|c|}
\hline Inorganic matrix & C Adsorbed water \\
\hline Organic matter & Free gas \\
\hline Free water & O Adsorbed gas \\
\hline
\end{tabular}

FIGURE 4: Schematic illustration of the effect of water content on the shale gas adsorption process: (a) shale matrix and (b) water injection process. The upper part of (a) represents the original state, and the lower part of (b) illustrates the changes induced by the water injection.

Therefore, the two-phase flow in a fracture system can be written as

$$
\begin{aligned}
& \frac{\partial\left(s_{f w} \rho_{f w} \phi_{f}\right)}{\partial t}=\nabla \cdot\left(\rho_{f w} \frac{k_{f} k_{f r w}}{\mu_{w}}\left(\nabla p_{f}+\rho_{f w} g\right)\right)+Q_{w f} \\
& \frac{\partial\left(s_{f g} \rho_{f g} \phi_{f}\right)}{\partial t}=\nabla\left(-\rho_{f g} \frac{k_{f} k_{f r g}}{\mu_{a}}\left(\nabla p_{f g}+\rho_{f w} g\right)\right) \\
&-\frac{\sigma_{\text {in }} k_{\text {apin }}}{\mu} \rho_{\text {in }}\left(p_{f}-p_{\text {in }}\right)
\end{aligned}
$$

3.2. Water Imbibition in the Inorganic Matrix. From microscopic images in some studies $[54,55]$, clay minerals in the shale matrix are usually embedded into nonclay minerals. Generally, a maximum water mass value exists, above which water mass remains constant, and the ratio of increase generally declines with the water mass content. Therefore, the rise in the water mass of clay minerals is determined by the disparity between the presented water mass $\left(m_{\mathrm{cl}}\right)$ and the maximum value $\left(m_{\max }\right)[50]$ :

$$
\frac{\partial m_{\mathrm{cl}}}{\partial t}= \begin{cases}R_{a}\left(m_{\max }-m_{d}\right), & \text { if } m_{\mathrm{cl}}<m_{\max } \\ 0, & \text { if } m_{\mathrm{cl}} \geq m_{\max }\end{cases}
$$

where $R_{a}$ refers to the adsorption rate $(1 / \mathrm{s})$.

3.3. Gas Slippage Flow in the Inorganic Matrix. The mass conservation law of gas slippage flow in an inorganic pore can be represented as [14]

$$
\frac{\partial m_{\text {ing }}}{\partial t}+\nabla \cdot J_{\text {ing }}=Q_{s}+Q_{\text {in } 2 f}
$$

where subscript in represents inorganic minerals and $J_{\text {ing }}$ refers to the gas mass flux.

Both the free-phase gas in inorganic pores and the gas mass source applied by the organic system contribute to the gas mass content $m_{\text {ing }}$ :

$$
m_{\text {ing }}=\rho_{\text {ing }} \phi_{\text {in }} S_{\text {ing }}+\rho_{\text {ga }} \rho_{s} m_{\text {or }}
$$

where $\varphi_{\text {in }}$ refers to the inorganic porosity and $\rho_{\text {ing }}$ refers to the gas density. $J_{\text {ing }}$ is described as the modified Darcy equation:

$$
J_{\text {ing }}=-\frac{k_{\text {apin }}}{\mu} \rho_{\text {ing }} \nabla p_{\text {in }}
$$

where $k_{\text {apin }}$ refers to the apparent permeability and is written as [2]

$$
k_{\text {apin }}=\left(1+\frac{4 \mathrm{Kn}_{\mathrm{in}}}{1+\mathrm{Kn}_{\mathrm{in}}}\right) k_{\mathrm{ing}} .
$$

3.4. Diffusion of Gas in Organic Matter. The mass transfer rate between the inorganic and organic systems depends on the diffusion duration in the organic matter [56].

$$
\frac{d m_{\mathrm{or}}}{d t}=-\frac{1}{\tau_{\mathrm{or}}}\left[m_{\mathrm{or}}-m_{\mathrm{eq}}\left(p_{\text {wall }}\right)\right]
$$

where $m_{\mathrm{eq}}\left(p_{\text {wall }}\right)$ represents the gas concentration at equipoise with the interface pressure $p_{\text {wall }}$. The diffusion time $\tau_{\text {or }}$ is represented as

$$
\tau_{\text {or }}=\frac{1}{\omega_{\text {or }} D_{\text {or }}},
$$




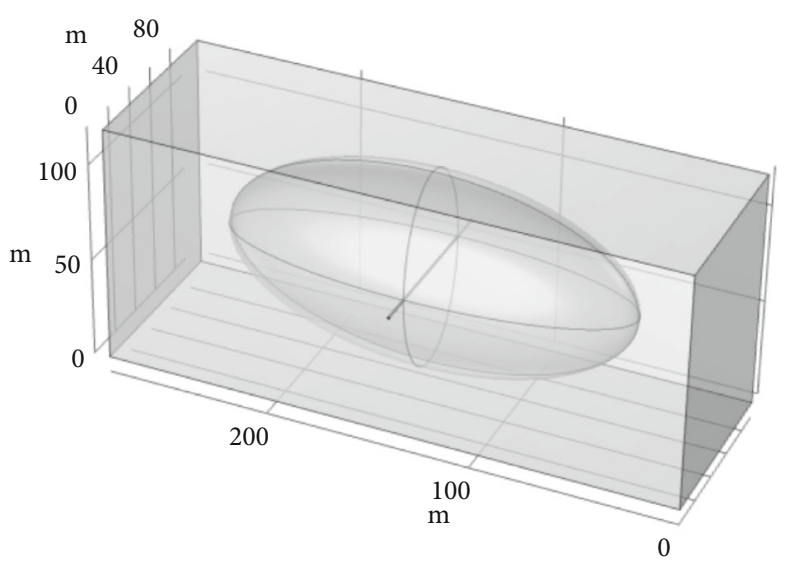

(a)

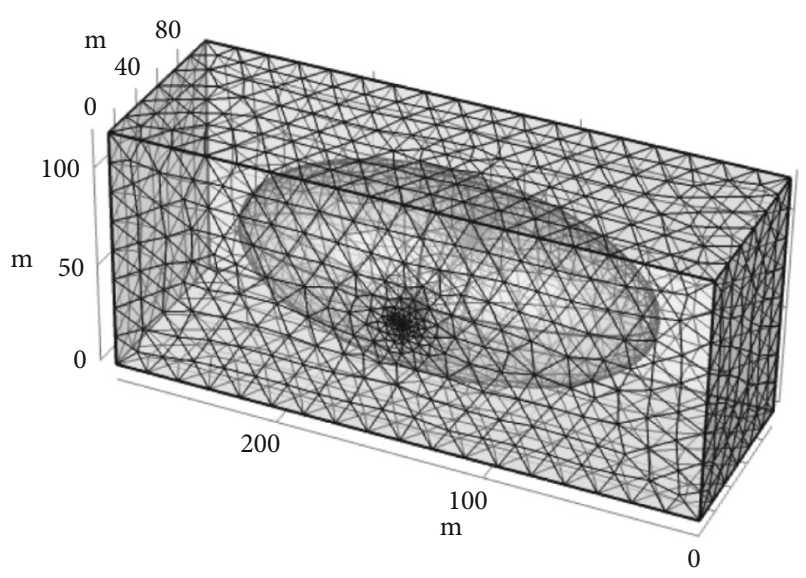

(b)

FIGURE 5: Illustration of the multiphysics, multidomain model: (a) geometric model and (b) meshing model.

where subscript or represents the organic matter, $D\left(\mathrm{~m}^{2} / \mathrm{s}\right)$ is the surface diffusion coefficient, and $w_{\text {or }}$ is the shape factor.

3.5. Competitive Adsorption in Organic Matter. We assumed a pseudosteady state in this work [31] and found that the interface pressure $p_{\text {wall }}$ was equivalent to the inorganic matrix pressure $p_{\text {or }}$. Because of the presence of clay minerals, a water film exists on the surface of minerals in inorganic shale [21, 57] influencing the adsorption and desorption behavior of shale gas. The following equation is proposed [58]:

$$
m_{\text {or }}=\beta \frac{V_{\mathrm{H}} p_{\text {or }}}{p_{\text {or }}+P_{\mathrm{H}}}+(1-\beta) \frac{V_{\mathrm{L}} p_{\text {or }}}{P_{\mathrm{L}}+p_{\text {or }}}
$$

where $m_{\text {or }}$ is the gas adsorption volume in organic matter, $V_{\mathrm{L}}$ refers to the solid-gas (Langmuir) saturated adsorption volume, $P_{\mathrm{L}}$ is the Langmuir pressure constant, $V_{\mathrm{H}}$ refers to the liquid-gas saturated adsorption capacity, and $\beta$ is the water molecular coverage ratio, defined as the rate of the wetting area of water molecules to the whole pore area. Moreover, the covering rate of the water molecules is relevant to irreducible water saturation, as shown by the following [59]:

$$
S_{r w}=\left[1-\left(1-\frac{h}{r}\right)^{2}\right] \beta,
$$

where $S_{w}$ refers to the capillary water saturation (dimensionless), $r$ refers to the pore radius, and $h$ refers to the water molecular layer thickness.

\subsection{Permeability Variation with Effective Stress and Water Saturation}

3.6.1. Permeability Correction with Water Saturation. The following supplementary equations for saturation and capillary pressure are necessary for solving the two-phase flow in a shale reservoir [60]:

$$
\begin{aligned}
& s_{i w}+s_{i g}=1, \\
& p_{i c}=p_{i g}-p_{i w},
\end{aligned}
$$

where $p_{i c}$ is the capillary pressure and calculated with the Brooks and Corey formulation $[61,62]$ :

$$
p_{i c}=p_{i e}\left(s_{i e w}\right)^{-1 / \lambda_{i}},
$$

where $p_{i e}$ represents the nonwetting phase entry pressure, $s_{i e w}$ represents the effective saturation for the water phase, and $\lambda_{i}$ represents a pore size distribution parameter. In our research, we assumed that the parameter $\lambda_{i}$ was 2 . Then, the effective water saturation can be expressed as

$$
s_{e w i}=\frac{s_{w i}-s_{w r i}}{1-s_{w r i}-s_{g r i}} \text {, }
$$

where $s_{w r i}$ and $s_{\text {gri }}$ represent the irreducible water and gas saturations in a fracture zone, respectively.

In this study, the relative permeability was governed by $[63]$

$$
\begin{aligned}
& k_{i r g}=\left(1-s_{i e w}\right)^{2}\left(1-s_{i e w}{ }^{2}\right), \\
& k_{\text {irw }}=\sqrt{s_{\text {iew }}}\left(1-\left(1-s_{\text {iew }}{ }^{1 / m}\right)^{m}\right)^{2},
\end{aligned}
$$

where $k_{i r g}$ and $k_{i r w}$ refer to the relative permeabilities of gas and water, respectively.

Water saturation can be determined directly for the twophase flow in a fracture system. The water saturation in clay minerals is related to the water mass and represented as

$$
S_{w \mathrm{cl}}=\frac{m_{\mathrm{cl}}}{m_{\max }} S_{w \max }
$$

where $S_{w \max }$ denotes the maximum water saturation in clay minerals. 
TABLE 1: Marcellus Shale property parameters $[66,67]$.

(a)

\begin{tabular}{lc}
\hline Reservoir parameter & Value \\
Reservoir temperature $\left({ }^{\circ} \mathrm{C}\right)$ & 79.4 \\
Fracturing cluster spacing $(\mathrm{m})$ & 92 \\
Size of the simulation area $($ rectangle, $\mathrm{m})$ & $92 \times 280 \times 120$ \\
Fracture permeability in SRV $\left(k_{f x}, \mathrm{~m}^{2}\right)$ & $1.5 \times 10^{-16}$ \\
Inorganic permeability in SRV $\left(k_{\text {in } x}, \mathrm{~m}^{2}\right)$ & $1.5 \times 10^{-18}$ \\
Fracture porosity in SRV & 0.07 \\
Inorganic porosity in SRV & 0.03 \\
Shape factor in the inorganic matrix $\left(\mathrm{m}^{-2}\right)$ & 15 \\
Initial water saturation in SRV & 0.05 \\
Irreducible water saturation & 0.06 \\
Langmuir pressure constant $(\mathrm{MPa})$ & 4 \\
Bottom-hole water saturation & 0.1 \\
General parameter & Value \\
Gas density $\left(\mathrm{kg} / \mathrm{m}^{3}\right)$ & 0.714 \\
Coefficient for relative permeability $(\mathrm{m})$ & 0.5 \\
Universal gas constant $(\mathrm{J} /(\mathrm{mol} \cdot \mathrm{K}))$ & 8.314 \\
Compressibility of methane $\left(\mathrm{Pa}{ }^{-1}\right)$ & $1.4 \times 10^{-5}$ \\
\hline
\end{tabular}

(b)

\begin{tabular}{lc}
\hline Reservoir parameter & Value \\
Bottom-hole pressure $(\mathrm{MPa})$ & 3.45 \\
Initial gas pressure $(\mathrm{MPa})$ & 32.6 \\
Size of SRV (spheroid, m) & $30 \times 100 \times 50$ \\
Fracture permeability in USRV $\left(k_{f x}, \mathrm{~m}^{2}\right)$ & $1.3 \times 10^{-18}$ \\
Inorganic permeability in USRV $\left(k_{\mathrm{in} x}, \mathrm{~m}^{2}\right)$ & $2 \times 10^{-20}$ \\
Fracture porosity in USRV & 0.04 \\
Inorganic porosity in USRV & 0.015 \\
Surface diffusion coefficient $(s)$ & $4 \times 10^{9}$ \\
Initial water saturation in USRV & 0.05 \\
Irreducible water saturation & 0.04 \\
Langmuir volume constant $\left(\mathrm{m}^{3} / \mathrm{kg}\right)$ & 0.003 \\
Biot's coefficient & 0.8 \\
General parameter & Value \\
Gas viscosity $(\mathrm{Pa} \cdot \mathrm{s})$ & $2 \times 10^{-5}$ \\
Coefficient for capillary pressure $(\lambda)$ & 2 \\
Molar mass of methane $\left(\mathrm{kg} / \mathrm{mol}^{2}\right)$ & 0.016 \\
Compressibility of methane $\left(\mathrm{Pa}{ }^{-1}\right)$ & $3.8 \times 10^{-10}$ \\
\hline
\end{tabular}

3.6.2. Permeability Correction with Effective Stress. The fracture permeability correlation for gas shale with effective stress can be written as

$$
k=k_{0} e^{-3 c_{f}\left(\sigma_{e f}-\sigma_{e f 0}\right)},
$$

where $\sigma_{e f}$ refers to the effective stress and $c_{f}$ refers to the

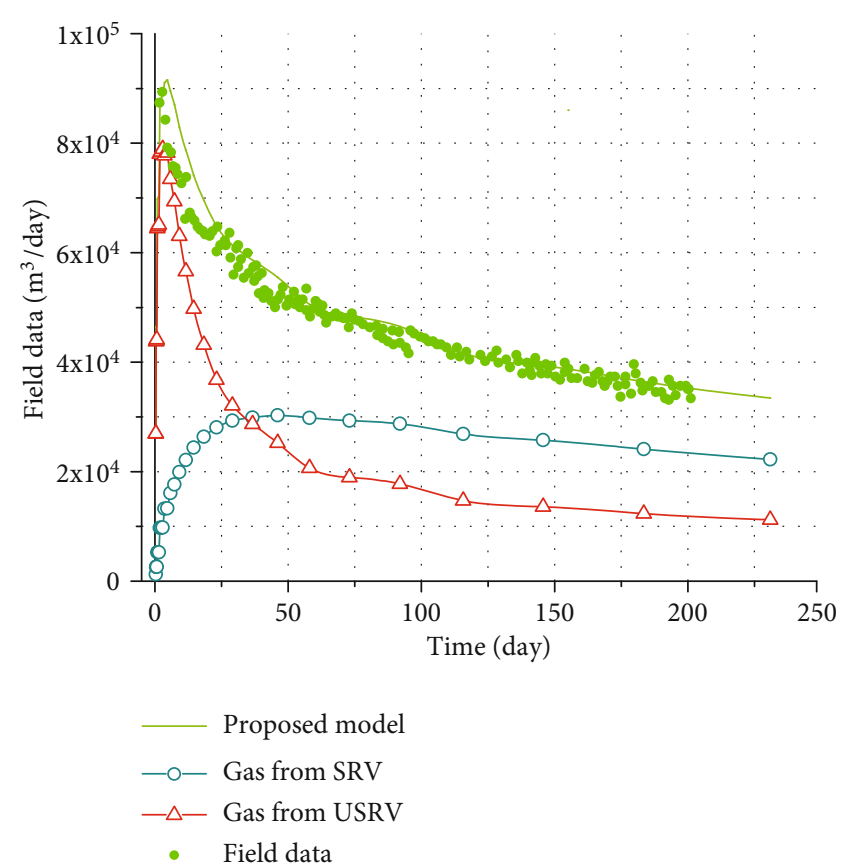

FIgURE 6: History matching results for field data gathered from the Marcellus Shale.

fracture compressibility. The effective stress, which represents the distinction between the formation stress and liquid pressure, can be formulated as

$$
\sigma_{e f}=\sigma-p
$$

The liquid pressure is the combination of the gas and water pressures in the fracture system, which is defined as follows:

$$
p=s_{w} p_{f w}+s_{g} p_{f g}
$$

and the inorganic system's gas pressure, which is defined as follows:

$$
p=p_{g}
$$

\section{Model Verification}

4.1. Model Building. A testing well drilled into the lower sections of the Marcellus Shale [64] executed seven fracturing stages (each of which contained five perforation clusters) measuring over $630 \mathrm{~m}$ in the lateral section. Its completion design included 450,000 gallons of slick water per stage, and sand particles were used as proppants. Only 200 days of the production data were used for history matching. The distance between the different fracture stages far outweighed that between diverse perforation clusters in a special stage $[29,57]$. Therefore, a computation domain including one fracture stage (five perforation clusters) and its adjacent area was selected. 


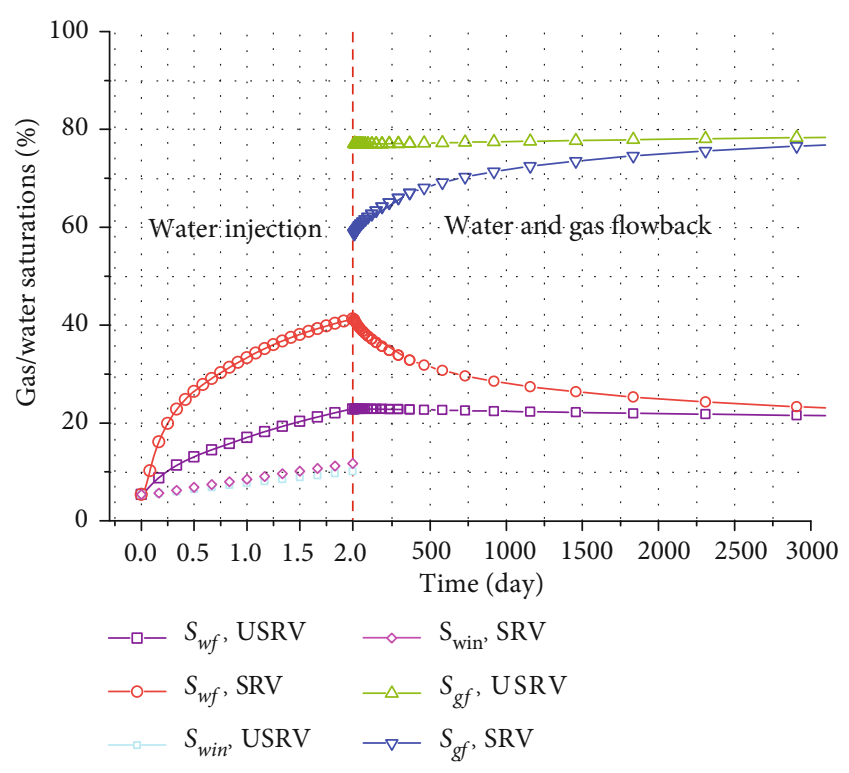

FIGURE 7: Evolution of average water saturation in the SRV and USRV regions.

Similar to Cui et al. [14], we connected the SRV areas induced per perforation cluster and formed a spheroidshaped volume. The nonimpacted area is the USRV. In the process of simulation model design, the research area was configured as a cuboid with a size of $92 \mathrm{~m} \times 280 \mathrm{~m} \times 120 \mathrm{~m}$, while the SRV exhibits spheroid shape with the semiaxes defined as 35,100 , and $50 \mathrm{~m}$ (in the $x, y$, and $z$ directions, respectively). The reservoir geometry and SRV are depicted in Figure 5(a). A highly refined mesh is required for the $S R V$ region, while a relatively coarser mesh is suitable for the USRV. After meshing, there were a total of 113,895 elements with an average quantity of 0.85 as depicted in Figure 5(b).

Both the water injection, which lasted two days, and the gas production processes were replicated to fully verify the proposed model. For the water injection process, a constant water saturation value of 0.8 was used as the water flow boundary. For the gas production process, the bottom-hole pressure was obtained from Meyer [65]. For the gas flow model in the organic and inorganic matrixes, due to the lack of immediate engagement with hydraulically formed fractures, flow boundary conditions were not taken into consideration. The water saturation value applied to the well was 0.2. Information about the Marcellus Shale reservoir was gathered from the previous work [66-68] and is detailed in Table 1.

4.2. Verification Results. The matched gas production ratios are shown in Figure 6 . The model perfectly matched the field data, with a goodness-of-fit value of 0.92 . The gas sources were also examined. As the production time increased, the gas production rate increased and then decreased. The increase stage was mainly observed in the first two days. This is because a large amount of water was discharged during this stage, which increased the relative gas permeability.

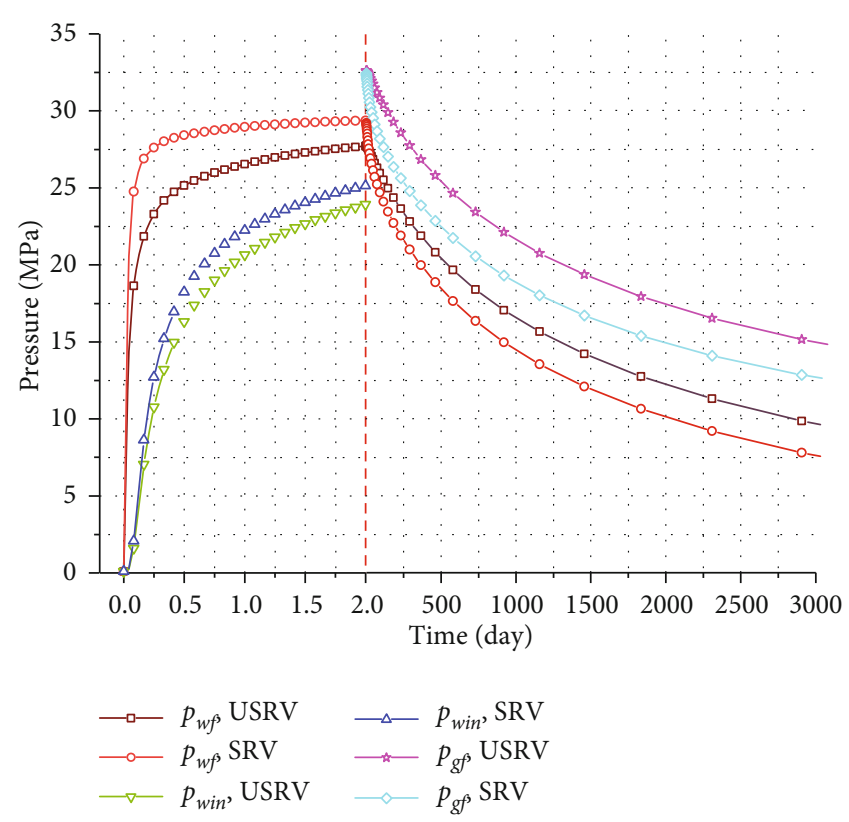

FIGURE 8: Evolution of average water pressure in the SRV and USRV regions during water injection.

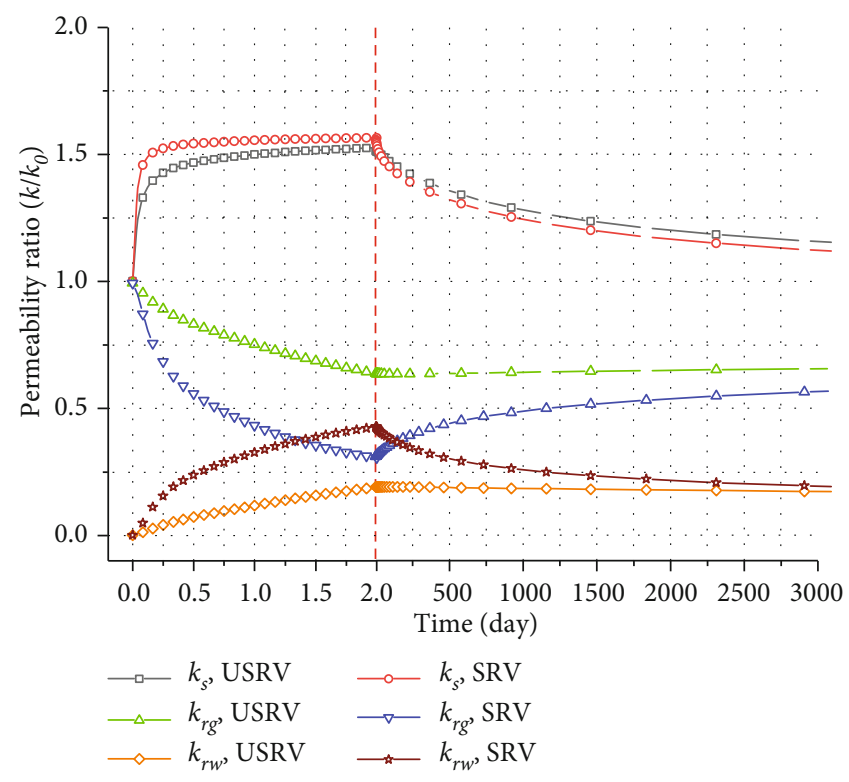

FIGURE 9: Gas/water relative permeability and intrinsic permeability of the SRV and USRV regions.

\section{Results and Discussion}

\subsection{Water and Gas Transport Processes}

5.1.1. Water and Gas Saturation Evolution. Changes in water and gas saturation directly affect gas and water relative permeabilities. In the water injection stage, the water pressure gradient forces the high-pressure water injected at the wellhead to migrate to the reservoir. Figure 7 shows the evolution of the $s_{w f}$ and $s_{w g}$ of the SRV and USRV regions. The average value of each domain is applied here. The 


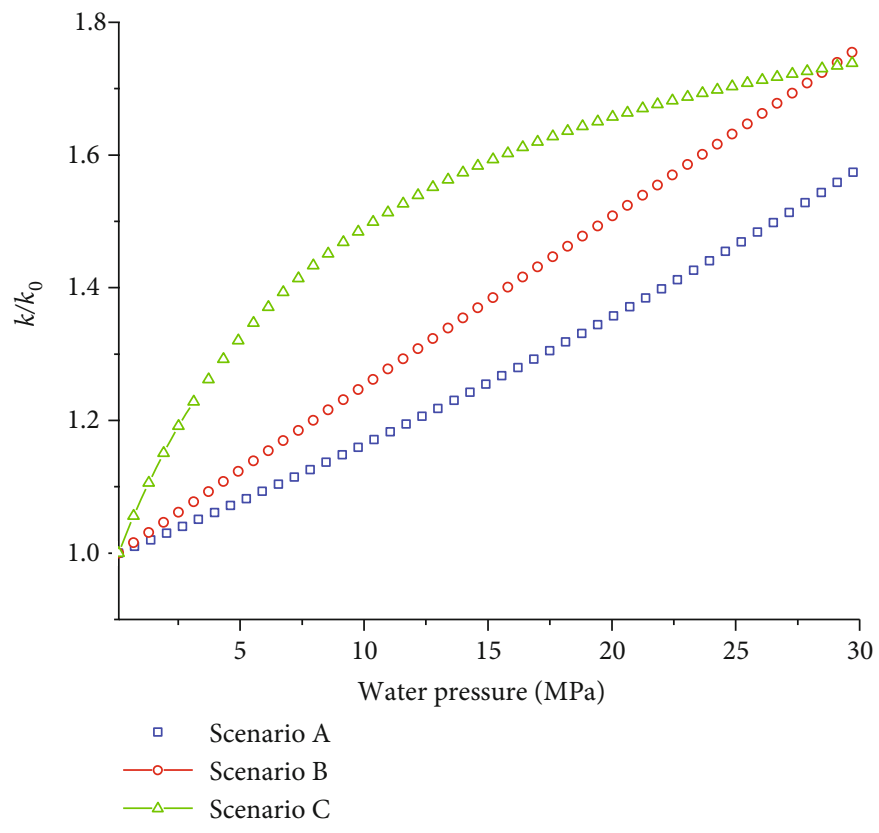

FIGURE 10: Intrinsic permeability variations with water pressure.

results show the following: (i) the values of $s_{w f}$ in the SRV and USRV regions show significant discrepancies, while the values of $s_{w i n}$ exhibit little differences. (ii) During the water flowback and gas production stage, the water in the fracture system first flows back, presenting a dramatic decrease in $s_{w f}$; by contrast, $s_{w i n}$ shows little variation. (iii) As a result, the gas saturation $\left(s_{g f}\right)$ in the fracture system spikes, but the value in the inorganic system shows only a small change.

5.1.2. Water and Gas Pressure Evolution. The water and gas pressures are further investigated to fully illustrate the water and gas transport processes in the shale reservoir. The average water and gas pressures of the fracture system in the SRV and USRV regions are shown in Figure 8. During the water injection stage, the water pressures of both systems significantly increase in not only the SRV region but also the USRV region; the values in the SRV system are larger than those in the USRV system. In the gas production process, the water and gas pressures drop sharply to the extraction pressure at the wellhead; the value in the SRV area is lower than that in the USRV area, leading to a pressure gradient. This pressure gradient causes the gas in the fracture to continuously migrate to the wellhead.

\subsection{Permeability Evolution}

5.2.1. Intrinsic Permeability Evolution. Permeability determines water and gas flow rates and therefore controls gas production characteristics. It is thus a significant parameter indicating the flow capacity in a reservoir. In this research, permeability is assumed as the combination of relative and intrinsic permeabilities, and their variations are examined.
Figure 9 shows the evolutions of intrinsic and relative permeabilities during the water injection and gas production stages. In the water injection stage, the effective stress increases, leading to an increment in intrinsic permeability. The value in the SRV area is larger than that in the USRV area due to the higher water pressure in the former region. During the water flowback and gas production stage, both intrinsic permeabilities in the SRV and USRV regions decline because of the decreased effective stress. On the contrary, the value in the SRV area is lower than that in the USRV area, but the difference is small because of the supporting effect of proppants.

5.2.2. Gas/Water Relative Permeability Evolution. Besides intrinsic permeability, the evolutions of relative permeabilities are illustrated. Gas and water relative permeabilities are directly related to water saturation, which is directly proportional to water relative permeability but inversely proportional to gas relative permeability. During the water injection process, water saturation continues to increase, leading to an increment in water relative permeability and a decline in gas relative permeability. In the water flowback and gas production stage, in the SRV region, the gas relative permeability rises as the water relative permeability is reduced. In the USRV area, the gas and water relative permeabilities do not change significantly. The gas relative permeability in the gas production stage is far below the original value, thereby hindering gas flow.

5.3. Impact of Water Pressure. As discussed above, gas production behavior is closely related to the evolution of intrinsic permeability and water injection pressure. This impact is further studied through three scenarios: (i) scenario A (benchmark model), where intrinsic permeability has an 


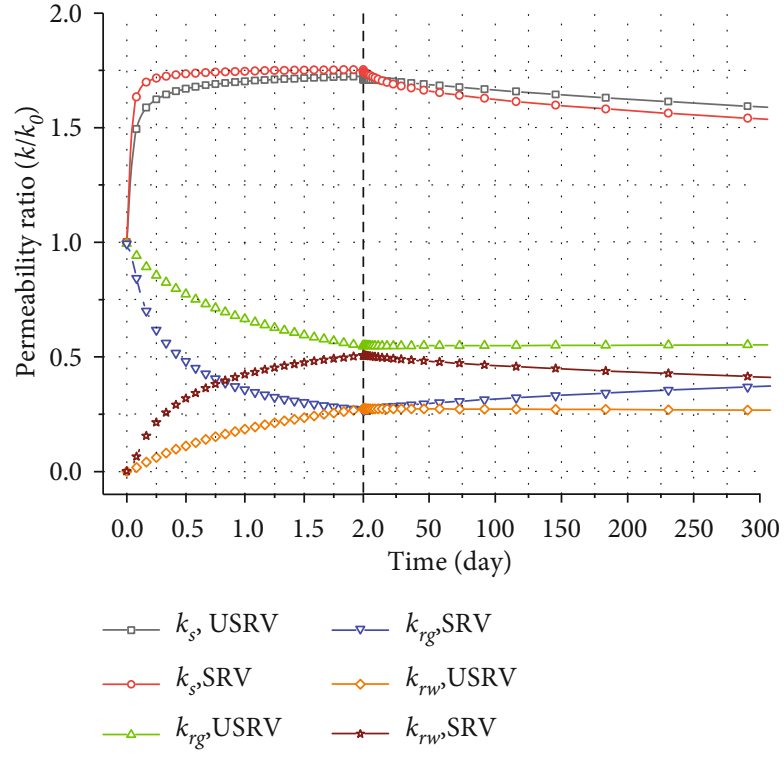

(a)

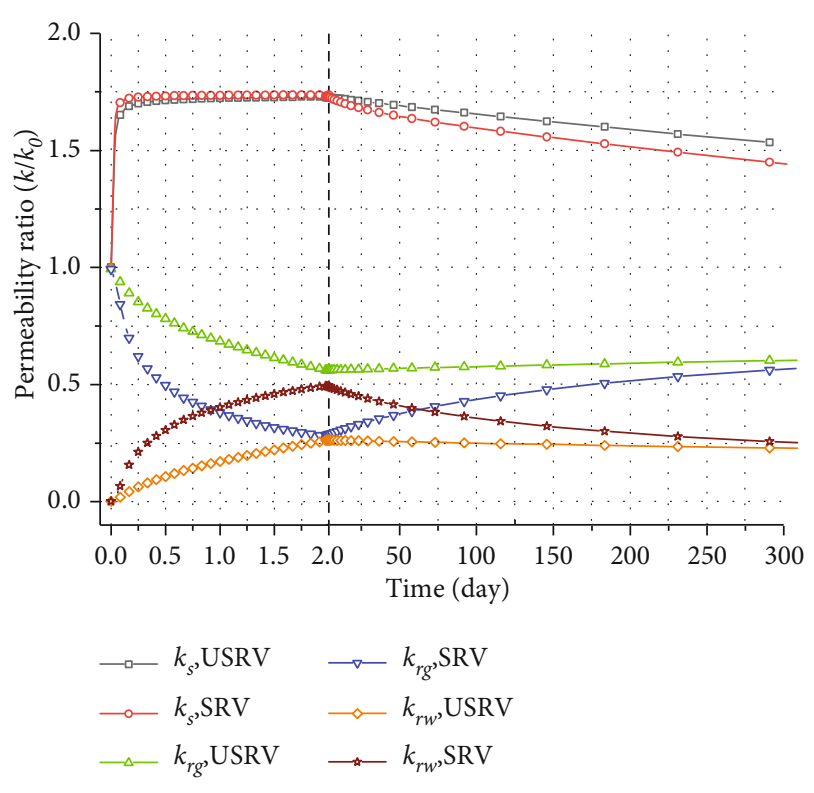

(b)

Figure 11: Gas/water relative permeability: (a) scenario B and (b) scenario C.

exponential relationship with water injection pressure; (ii) scenario $\mathrm{B}$, where intrinsic permeability is linearly proportional to water injection pressure; and (iii) scenario C, where intrinsic permeability has a Langmuir function relationship with water injection pressure. The equations of the abovementioned three scenarios could be found in Appendix A with the relationship illustrated in Figure 10.

Figure 11 depicts the evolution of the intrinsic permeability and water/gas relative permeabilities of scenarios B and C. Comparison of Figures 9 and 11(a) shows that during water injection, the intrinsic permeability in scenario $B$ is greater than that in scenario A; more water is injected into the fracture, thereby increasing the water saturation. Consequently, the water relative permeability rises, and the gas relative permeability declines. As seen in Figure 11(b), the intrinsic permeability obtained using the Langmuir function (scenario $\mathrm{C}$ ) is greater than that acquired using the exponential function (scenario B), leading to a larger gas relative permeability and less water relative permeability. Comparing Figures 11(a) and 11(b), we find that the intrinsic permeability shows little difference between two scenarios, but its difference between the SRV and USRV regions is smaller in scenario C. In addition, the gas permeability of scenario $\mathrm{C}$ is significantly larger than that of scenario $\mathrm{B}$.

Figure 12 illustrates the gas production rates of three scenarios. As observed in the figure, scenario $\mathrm{C}$ exhibits the highest production rate in the early production stage and then dramatically declines. This is because the intrinsic permeability obtained using the Langmuir function is significantly higher than that of the two other scenarios at the same downward pressure. Scenario B behaves most poorly during the whole production process. The main reason is that the linear growth of intrinsic permeability, which is greater than the exponential rise of permeability at the same water pressure, causes more water to be injected into

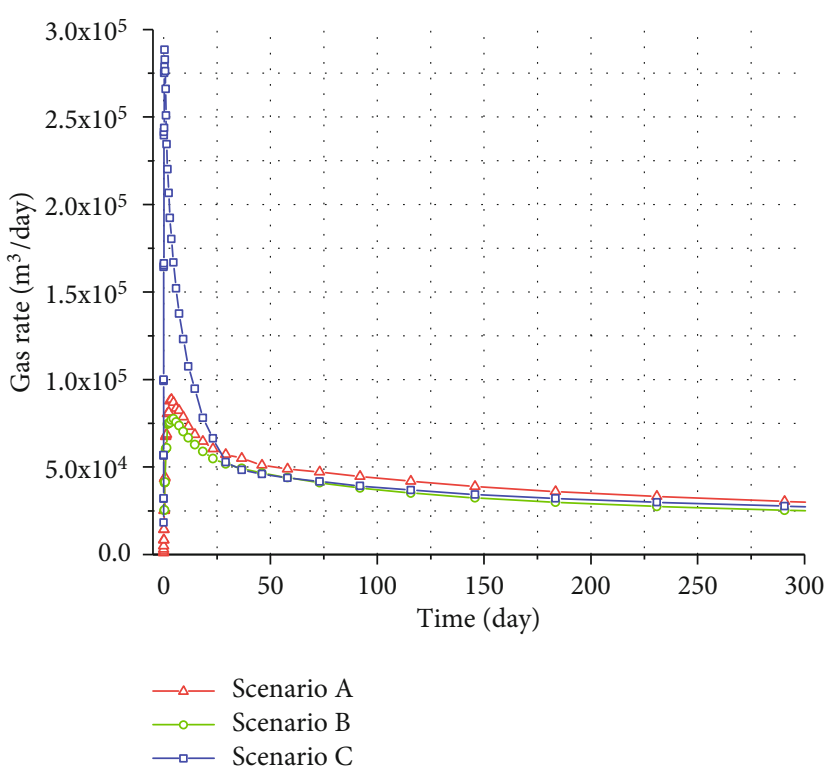

FIGURE 12: Gas production ratios of the three scenarios.

the fracture, which reduces the gas relative permeability. Under their combined effects, gas production is reduced.

5.4. Effect of Water Injection Time. The following scenarios are designed to sufficiently examine the effect of injection time on the gas production ratio: (i) scenario A (benchmark model), where intrinsic permeability is not affected by the water injection time; (ii) scenario $\mathrm{B}$, where intrinsic permeability is linearly proportional to the water injection time; and (iii) scenario C, where intrinsic permeability has a Langmuir function relationship with the water injection time. The equations of the abovementioned three scenarios 


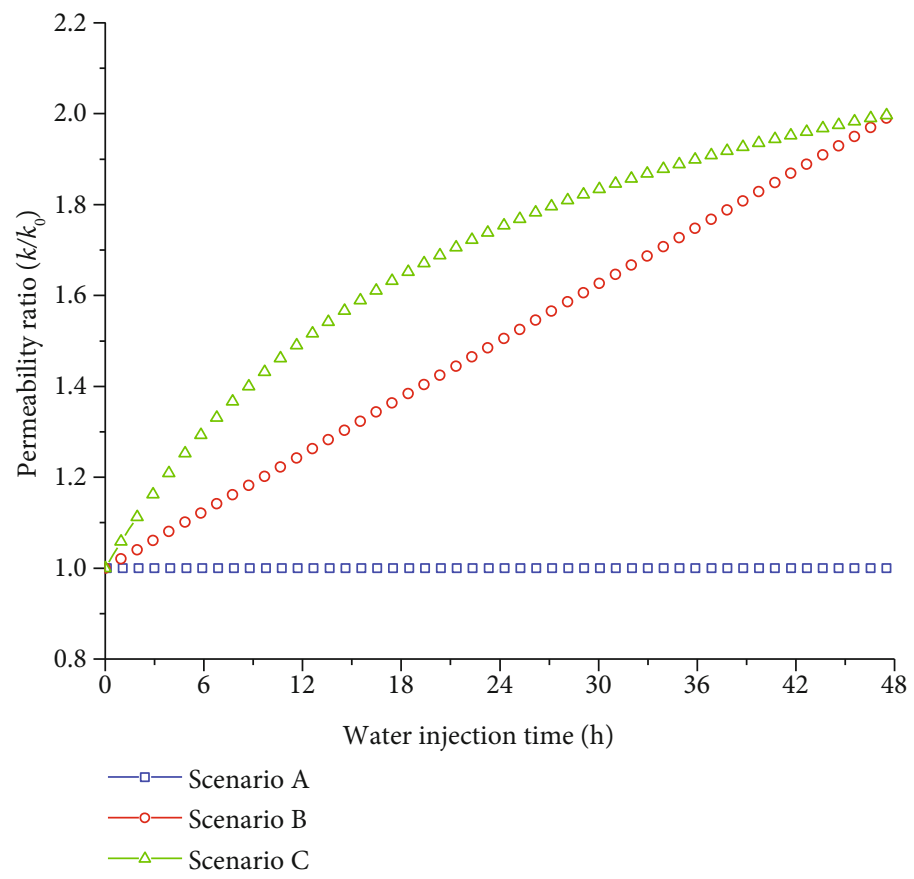

FIGURE 13: Intrinsic permeability variations with injection time.

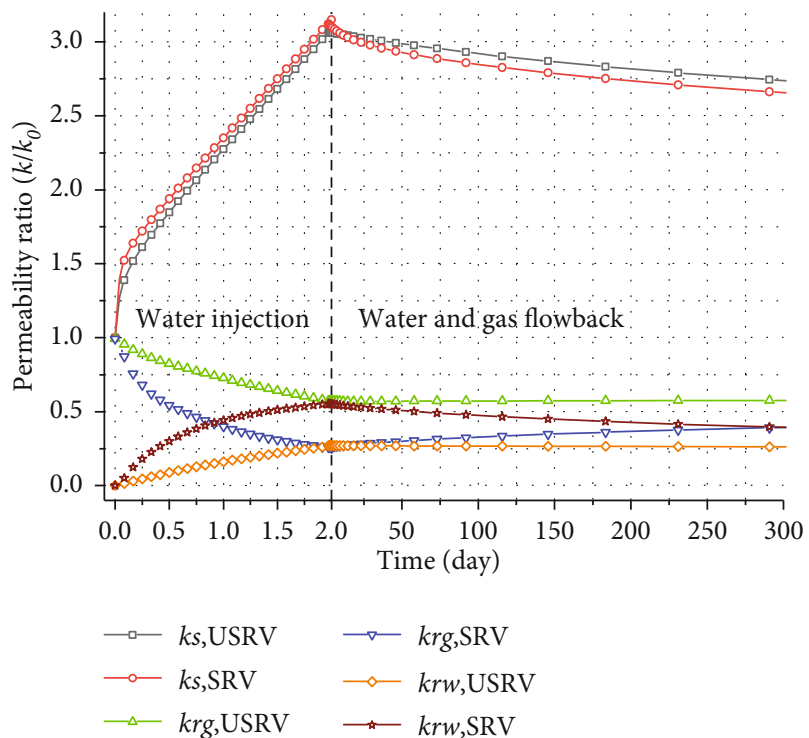

(a)

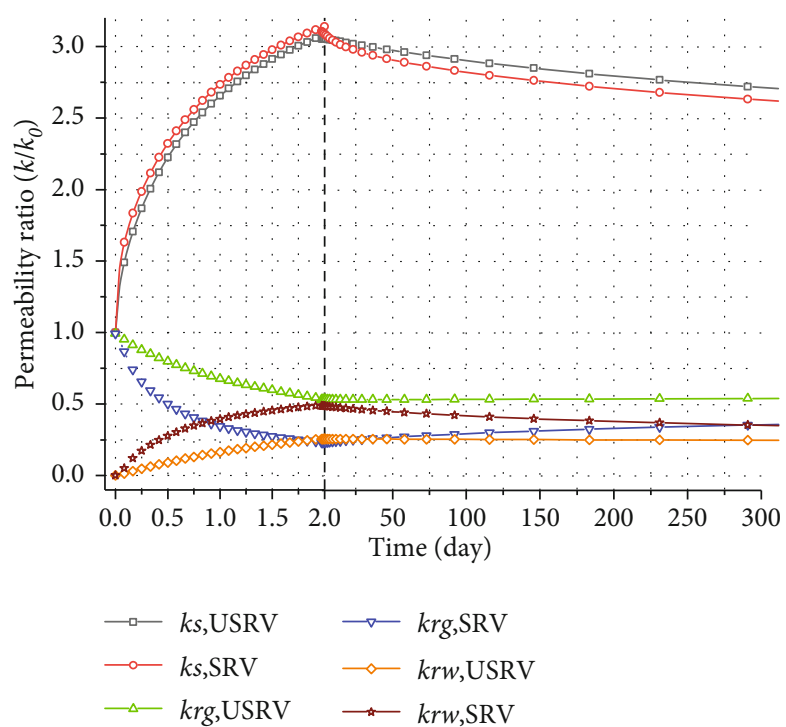

(b)

Figure 14: Gas/water relative permeability: (a) scenario B and (b) scenario C.

could be found in Appendix B with the relationship illustrated in Figure 13.

Figure 14 illustrates the evolutions of the intrinsic permeabilities and water/gas relative permeabilities of scenarios $\mathrm{B}$ and C. Comparison of Figures 9 and 14 indicate that during water injection, the intrinsic permeability of scenario $B$ is almost twice that of scenario A. Therefore, after the water injection is completed, the water relative permeabilities in scenarios $\mathrm{B}$ and $\mathrm{C}$ are higher than that in scenario $\mathrm{A}$.
Figure 15 illustrates the gas production rates of the three scenarios. From the figure, we can conclude that the production of scenarios B and C is significantly higher than that of scenario $\mathrm{A}$. This is because the inherent intrinsic permeabilities of scenarios B and C are almost double that of scenario $\mathrm{A}$ after the water injection is completed. The gas production of scenario B is slightly higher than that of scenario C. The reason is that in scenario $\mathrm{C}$, more water is injected, and the relative gas permeability is reduced. 


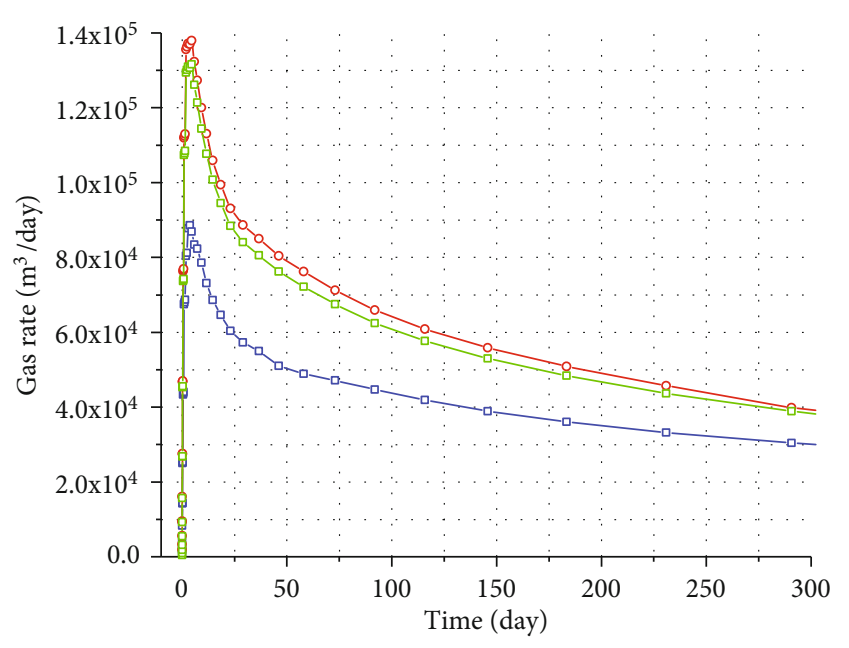

$\longrightarrow$ Scenario A
$\square$ Scenario B
$\square-$ Scenario C

Figure 15: Gas production ratio of the three scenarios.

5.5. Comprehensive Effect of Water Injection Pressure and Time. The comprehensive influences of water injection time and pressure on the gas depletion characteristic are examined by designing and solving nine computation scenarios. The water injection times are specified as 24,48 , and $72 \mathrm{~h}$ with the injection pressures defined as 20, 25, and $30 \mathrm{MPa}$. These two influencing factors are combined, and nine scenarios are obtained. In all scenarios, the intrinsic permeability has an exponential relationship with the water injection pressure and a linear relationship with the water injection time. The gas production ratios are shown in Figure 16. The gas production rate exhibits large differences between the scenarios, but no general variation laws can be identified. The scenario with $25 \mathrm{MPa}$ and $48 \mathrm{~h}$ and the scenario with $30 \mathrm{MPa}$ and $24 \mathrm{~h}$ show the largest gas production rates. The lowest values are observed in the scenario with $30 \mathrm{MPa}$ and $48 \mathrm{~h}$ and the scenario with $30 \mathrm{MPa}$ and $72 \mathrm{~h}$. The performance of the rest of the scenarios is ranked randomly.

The nine scenarios are randomly arranged for the following reasons. As discussed above, both intrinsic and relative permeabilities affect gas production. In these nine scenarios, a larger injection pressure and longer injection time will result in a larger intrinsic permeability, thus enhancing gas flow. On the contrary, a higher intrinsic permeability will allow more water to flow into the reservoir, thereby decreasing gas relative permeability and hindering gas flow. Therefore, the gas production behavior is dominated by two competing mechanisms: increased intrinsic permeability and reduced gas relative permeability. Therefore, the impact of water injection pressure and water injection time on gas production should be considered systematically when designing HF and gas production processes. A higher water injection pressure and longer water injection time could improve reservoir intrinsic permeability to a greater extent; however, it would simultaneously cause more water to enter the reservoir and reduce the relative gas permeability, thereby dampening gas production.

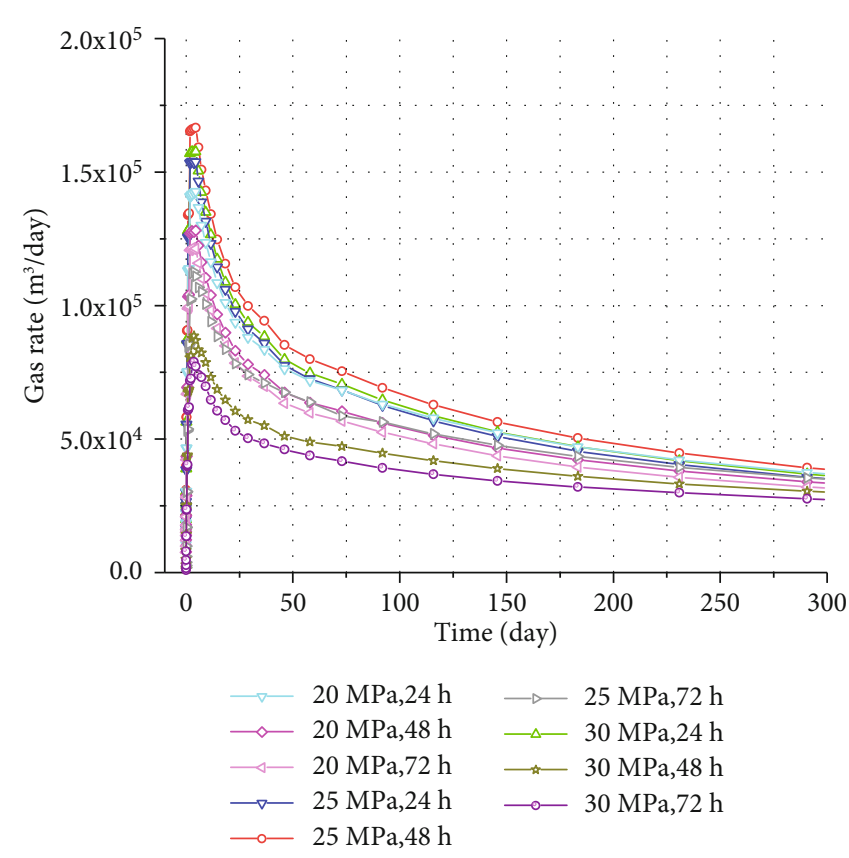

FIGURE 16: Evolution of the gas production ratio at different water injection pressures and water injection times.

\subsection{Limitations}

5.6.1. Assumed Permeability Relationships. In this work, the relationships between reservoir intrinsic permeability, water injection pressure, and water injection time are artificially assumed and two different forms are proposed. Generally, the maximum tensile stress criterion or the Mohr-Coulomb criterion is applied to describe the permeability evolutions during the hydraulic fracturing process, while the main job of this work is to provide a feasible approach to investigate the impact of water injection or gas production. To achieve this goal, the complicated damage process is not considered.

5.6.2. Intrinsic Permeability Model. In this work, a simple function (Eq. (22)) was adopted to describe the intrinsic permeability evolution in not only the water injection process but also the gas production process. This approach ignores the impacts of gas adsorption, interactions between matrix and fracture systems, and in situ geostress. This would certainly affect the determined gas production characteristics. Nonetheless, this impact is negligible for the following reasons: (i) compared with coalbed methane, the gas adsorption behavior is much smaller and has little impact on the gas permeability evolution. (ii) The interactions between matrix and fracture systems change the way permeability evolves but not its trend. (iii) In situ geostress changes due to water injection and gas production are not considered in this work. Only the change in effective stress created by pore pressure variations is studied. This work focuses on the effect of water injection pressure and time, instead of permeability laws, on gas production characteristics. Therefore, a convenient and widely used permeability model was applied. 


\section{Summary and Conclusions}

A triple-porosity, two-phase flow model was established and applied in this paper to examine the impact of hydraulic water on shale gas production characteristics. Different from the previous works which only investigate the water injection process, we paid our attention to the whole shale gas exploration process-both water injection and gas depletion processes. In particular, the evolutions of both intrinsic and relative permeabilities were investigated. According to the results of the studied case and numeric simulations, the following conclusions were drawn:

(1) A shale reservoir can be divided into a fracture system, inorganic matrix, and organic matrix. HF fluid enters the fracture and inorganic matrix, with connate water existing in the inorganic matrix and organic matter. History matching with field gas production data verified that the proposed model can be applied to describe the evolution of physical quantities in not only the water injection stage but also the gas production stage in a shale reservoir

(2) The evolutions of both relative and intrinsic permeabilities in the hydraulic fracturing and gas depletion processes were studied. The water relative permeability increases in the reservoir stimulation process due to water imbibition and then declines in the gas production stage. On the contrary, the gas relative permeability is below the original value because of the water imbibition. The intrinsic permeability increases during water injection but decreases during gas production

(3) Gas production behavior is dominated by two competing mechanisms. Increasing the water injection pressure and prolonging the water injection time would produce more cracks, thereby increasing intrinsic permeability; more water will enter the cracks and inorganic matter, thus restricting gas production. For maximum efficiency of gas extraction, the perfect combination of an appropriate injection time and injection pressure was devised in the current simulation

(4) The relationships of intrinsic permeability with water injection pressure and water injection time were particularly specified. However, the details of these relationships remain debatable, and more work is required. Nonetheless, this work can shed light on the field application of HF

\section{Appendix}

\section{A. Relationship of Permeability with Water Injection Pressure}

The specific expressions and parameter values of scenarios B and $\mathrm{C}$ were as follows:
Scenario B: linear relationship

$$
\frac{k}{k_{0}}=1+c_{f} \times\left(p_{w}-p_{0}\right),
$$

where $p_{0}=0.1 \mathrm{MPa}$ and $c_{f}=0.0255 \mathrm{MPa}^{-1}$.

Scenario C: Langmuir function relationship

$$
\frac{k}{k_{0}}=1+\left(\frac{p}{p+p_{l}}-\frac{p_{0}}{p_{0}+p_{l}}\right)
$$

where $p_{l}=10 \mathrm{MPa}$.

The intrinsic permeability variations with respect to the water injection pressure of the three scenarios are shown in Figure 10. As illustrated in the figure, the value of scenario $\mathrm{C}$ is the largest and that of scenario $\mathrm{A}$ is the smallest.

\section{B. Relationship of Permeability with Water Injection Time}

The specific expressions and parameter values were as follows:

Scenario B: linear relationship

$$
\frac{k}{k_{0}}=1+\alpha \times t,
$$

where $\alpha=1 / 48 \mathrm{~h}^{-1}$.

Scenario C: Langmuir function relationship

$$
\frac{k}{k_{0}}=1+\left(1.5 \times \frac{t}{t+\beta}\right),
$$

where $\beta=24 \mathrm{~h}$.

\section{Nomenclature}

$\begin{array}{ll}m: & \text { Flow mass } \\ p: & \text { Pressure } \\ \rho: & \text { Density } \\ S: & \text { Saturation } \\ J: & \text { Mass flux } \\ V_{\mathrm{L}}: & \text { Solid-gas saturated adsorption volume } \\ V_{\mathrm{H}}: & \text { Liquid-gas saturated adsorption capacity } \\ r: & \text { Pore radius } \\ \lambda: & \text { Pore size distribution parameter } \\ \omega: & \text { Shape factor } \\ \mathrm{g}: & \text { Gravitational acceleration } \\ \mu: & \text { Viscosity } \\ \varphi: & \text { Porosity } \\ Q: & \text { Flow source or sink } \\ \mathrm{Kn}: & \text { Knudsen number } \\ P_{\mathrm{L}}: & \text { Adsorption pressure constant } \\ \beta: & \text { Water molecular coverage ratio } \\ h: & \text { Water molecular layer thickness } \\ \sigma: & \text { Stress } \\ c_{f}: & \text { Fracture compressibility }\end{array}$




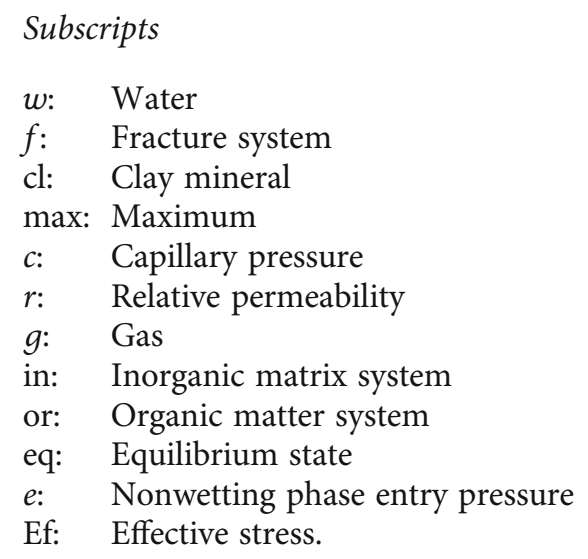

\section{Data Availability}

All data included in this study are available upon request by contact with the corresponding author.

\section{Conflicts of Interest}

We declare that there are no commercial (or related) interests and any other conflict of interest regarding the submitted work.

\section{Acknowledgments}

This research was advocated by the China Postdoctoral Science Foundation (Grant No. 2019M661118) and the “111” Project (Grant No. B17009).

\section{References}

[1] A. Vafaie, B. Habibnia, and S. A. Moallemi, "Experimental investigation of the pore structure characteristics of the Garau gas shale formation in the Lurestan Basin, Iran," Journal of Natural Gas Science and Engineering, vol. 27, pp. 432-442, 2015.

[2] G. Cui, J. Liu, M. Wei, X. Feng, and D. Elsworth, "Evolution of permeability during the process of shale gas extraction," Journal of Natural Gas Science and Engineering, vol. 49, pp. 94-109, 2018.

[3] G. Cui, J. Liu, M. Wei, R. Shi, and D. Elsworth, "Why shale permeability changes under variable effective stresses: new insights," Fuel, vol. 213, pp. 55-71, 2018.

[4] S. Wang, C. Qin, Q. Feng, F. Javadpour, and Z. Rui, "A framework for predicting the production performance of unconventional resources using deep learning," Applied Energy, vol. 295, article 117016, 2021.

[5] Y. Cheng, "Impact of water dynamics in fractures on the performance of hydraulically fractured wells in gas-shale reservoirs," Journal of Canadian Petroleum Technology, vol. 51, no. 2, pp. 143-151, 2012.

[6] J. Xu, L. Xu, and Y. Qin, "Two effective methods for calculating water saturations in shale-gas reservoirs," Geophysics, vol. 82, no. 3, pp. D187-D197, 2017.

[7] J. Li, Z. X. Chen, X. F. Li et al., "A quantitative research of water distribution characteristics inside shale and clay nanopores," Scientia Sinica Technologica, vol. 48, no. 11, pp. 1219-1233, 2018.
[8] H. Xiong, D. Devegowda, and L. Huang, "Water bridges in clay nanopores: mechanisms of formation and impact on hydrocarbon transport," Langmuir, vol. 36, no. 3, pp. 723-733, 2020.

[9] J. Li, X. Li, K. Wu et al., "Water sorption and distribution characteristics in clay and shale: effect of surface force," Energy \& Fuels, vol. 30, no. 11, pp. 8863-8874, 2016.

[10] H. Yanagihara, K. Yamashita, A. Endo, and H. Daiguji, "Adsorption-desorption and transport of water in twodimensional hexagonal mesoporous silica," The Journal of Physical Chemistry C, vol. 117, no. 42, pp. 21795-21802, 2013.

[11] F. P. Wang and R. M. Reed, "Pore networks and fluid flow in gas shales," in SPE Annual Technical Conference and Exhibition, p. 8, New Orleans, Louisiana, 2009.

[12] D. A. Handwerger, D. M. Willberg, M. Pagels, B. Rowland, and J. F. Keller, "Reconciling retort versus Dean Stark measurements on tight shales," in SPE Annual Technical Conference and Exhibition, p. 14, San Antonio, Texas, USA, 2012.

[13] L. Xinjing, H. Suyun, and C. Keming, "Suggestions from the development of fractured shale gas in North America," Petroleum Exploration and Development, vol. 34, p. 2, 2007.

[14] G. Cui, Y. Tan, T. Chen et al., "Multidomain two-phase flow model to study the impacts of hydraulic fracturing on shale gas production," Energy \& Fuels, vol. 34, no. 4, pp. 42734288, 2020.

[15] W. Yuan, X. Li, Z. Pan, L. D. Connell, S. Li, and J. He, "Experimental investigation of interactions between water and a lower Silurian Chinese shale," Energy \& Fuels, vol. 28, no. 8, pp. 4925-4933, 2014.

[16] T. Zhang, X. Li, Z. Sun et al., "An analytical model for relative permeability in water-wet nanoporous media," Chemical Engineering Science, vol. 174, pp. 1-12, 2017.

[17] R. van Noort and V. Yarushina, "Water, $\mathrm{CO}_{2}$ and argon permeabilities of intact and fractured shale cores under stress," Rock Mechanics and Rock Engineering, vol. 52, no. 2, pp. 299-319, 2019.

[18] J. Gao and Z. Li, "Water saturation-driven evolution of helium permeability in Carboniferous shale from Qaidam Basin, China: an experimental study," Marine and Petroleum Geology, vol. 96, pp. 371-390, 2018.

[19] M. Achang, J. C. Pashin, and E. A. Atekwana, "The influence of moisture on the permeability of crushed shale samples," Petroleum Science, vol. 16, no. 3, pp. 492-501, 2019.

[20] J. Zhang, Q. Feng, X. Zhang, Q. Hu, J. Yang, and N. Wang, “A novel data-driven method to estimate methane adsorption isotherm on coals using the gradient boosting decision tree: a case study in the Qinshui Basin, China," Energies, vol. 13, no. 20, p. $5369,2020$.

[21] Z. Jin and A. Firoozabadi, "Effect of water on methane and carbon dioxide sorption in clay minerals by Monte Carlo simulations," Fluid Phase Equilibria, vol. 382, pp. 10-20, 2014.

[22] J. Li, S. Wang, S. Lu et al., "Microdistribution and mobility of water in gas shale: a theoretical and experimental study," Marine and Petroleum Geology, vol. 102, pp. 496-507, 2019.

[23] M. Gasparik, P. Bertier, Y. Gensterblum, A. Ghanizadeh, B. M. Krooss, and R. Littke, "Geological controls on the methane storage capacity in organic-rich shales," International Journal of Coal Geology, vol. 123, pp. 34-51, 2014.

[24] Z. Liu, D. Liu, Y. Cai, Y. Yao, Z. Pan, and Y. Zhou, "Application of nuclear magnetic resonance (NMR) in coalbed methane and shale reservoirs: A review," International Journal of Coal Geology, vol. 218, article 103261, 2020. 
[25] L. Wang and Q. Yu, "The effect of moisture on the methane adsorption capacity of shales: a study case in the eastern Qaidam Basin in China," Journal of Hydrology, vol. 542, pp. 487-505, 2016.

[26] C. R. Clarkson and J. Williams-Kovacs, "Modeling two-phase flowback of multifractured horizontal wells completed in shale," SPE Journal, vol. 18, no. 4, pp. 795-812, 2013.

[27] J. Zhang, Q. Feng, X. Zhang et al., "Multi-fractured horizontal well for improved coalbed methane production in eastern Ordos basin, China: field observations and numerical simulations," Journal of Petroleum Science and Engineering, vol. 194, article 107488, 2020.

[28] J. Williams-Kovacs and C. Clarkson, "A modified approach for modelling 2-phase flowback from multi-fractured horizontal shale gas wells. Unconventional Resources Technology Conference," in Unconventional Resources Technology Conference, San Antonio, Texas, USA, 2015.

[29] R. Yang, Z. Huang, G. Li et al., "An innovative approach to model two-phase flowback of shale gas wells with complex fracture networks," in SPE Annual Technical Conference and Exhibition, Dubai, 2016.

[30] X. Shang, J. Wang, and Z. Zhang, "Iterative analytical solutions for nonlinear two-phase flow with gas solubility in shale gas reservoirs," Geofluids, vol. 2019, Article ID 4943582, 15 pages, 2019.

[31] G. Cui, F. Xia-Ting, Z. Pan et al., "Impact of shale matrix mechanical interactions on gas transport during production," Journal of Petroleum Science and Engineering, vol. 184, article 106524, 2020.

[32] Y. Luo and J.-P. Ampuero, "Stability of faults with heterogeneous friction properties and effective normal stress," Tectonophysics, vol. 733, pp. 257-272, 2018.

[33] P. Cao, J. Liu, and Y.-K. Leong, "A multiscale-multiphase simulation model for the evaluation of shale gas recovery coupled the effect of water flowback," Fuel, vol. 199, pp. 191-205, 2017.

[34] W. Li, J. Liu, J. Zeng, Y. K. Leong, and D. Elsworth, "A fully coupled multidomain and multiphysics model for shale gas production," in 5th ISRM Young Scholars' Symposium on Rock Mechanics and International Symposium on Rock Engineering for Innovative Future, Okinawa, Japan, 2019.

[35] W. Li, J. Liu, J. Zeng et al., "A fully coupled multidomain and multiphysics model for evaluation of shale gas extraction," Fuel, vol. 278, article 118214, 2020.

[36] C. Chen, D. Hu, D. Westacott, and D. Loveless, "Nanometerscale characterization of microscopic pores in shale kerogen by image analysis and pore-scale modeling," Geochemistry Geophysics Geosystems, vol. 14, no. 10, pp. 4066-4075, 2013.

[37] A. Mehmani, M. Prodanović, and F. Javadpour, "Multiscale, multiphysics network modeling of shale matrix gas flows," Transport in Porous Media, vol. 99, no. 2, pp. 377-390, 2013.

[38] R. J. Ambrose, R. C. Hartman, M. D. Campos, I. Y. Akkutlu, and C. Sondergeld, "New pore-scale considerations for shale gas in place calculations," in SPE Unconventional Gas Conference, Pittsburgh, Pennsylvania, USA, 2010.

[39] I. Y. Akkutlu and E. Fathi, "Multiscale gas transport in shales with local kerogen heterogeneities," SPE Journal, vol. 17, no. 4, pp. 1002-1011, 2012.

[40] A. Wasaki and I. Y. Akkutlu, "Permeability of organic-rich shale," in SPE Annual Technical Conference and Exhibition, Amsterdam, The Netherlands, 2014.

[41] S. Wang, Q. Feng, F. Javadpour, M. Zha, and R. Cui, "Multiscale modeling of gas transport in shale matrix: an integrated study of molecular dynamics and rigid-pore-network model," SPE Journal, vol. 25, no. 3, pp. 1416-1442, 2020.

[42] S. Wang, X. Yao, Q. Feng et al., "Molecular insights into carbon dioxide enhanced multi-component shale gas recovery and its sequestration in realistic kerogen," Chemical Engineering Journal, vol. 425, article 130292, 2021.

[43] J. G. Wang, Y. Ju, F. Gao, and J. Liu, "A simple approach for the estimation of $\mathrm{CO}_{2}$ penetration depth into a caprock layer," Journal of Rock Mechanics and Geotechnical Engineering, vol. 8, no. 1, pp. 75-86, 2016.

[44] A. Millard, A. Bond, S. Nakama, C. Zhang, J.-D. Barnichon, and B. Garitte, "Accounting for anisotropic effects in the prediction of the hydro-mechanical response of a ventilated tunnel in an argillaceous rock," Journal of Rock Mechanics and Geotechnical Engineering, vol. 5, no. 2, pp. 97-109, 2013.

[45] P. Tan, Y. Jin, K. Han et al., "Analysis of hydraulic fracture initiation and vertical propagation behavior in laminated shale formation," Fuel, vol. 206, pp. 482-493, 2017.

[46] G. Cui, J. Wei, X.-T. Feng et al., "Preliminary study on the feasibility of co-exploitation of coal and uranium," International Journal of Rock Mechanics and Mining Sciences, vol. 123, article 104098, 2019.

[47] T. Y. Chen, X. T. Feng, and Z. J. Pan, "Experimental study of swelling of organic rich shale in methane," International Journal of Coal Geology, vol. 150-151, pp. 64-73, 2015.

[48] T. Chen, X.-T. Feng, and Z. Pan, "Experimental study on kinetic swelling of organic-rich shale in $\mathrm{CO}_{2}, \mathrm{CH}_{4}$ and $\mathrm{N}_{2}$," Journal of Natural Gas Science and Engineering, vol. 55, pp. 406-417, 2018.

[49] F. Yang, C. Xie, Z. Ning, and B. M. Krooss, "High-pressure methane sorption on dry and moisture-equilibrated shales," Energy \& Fuels, vol. 31, no. 1, pp. 482-492, 2017.

[50] T. Ma, K. Zhang, W. Shen, C. Guo, and H. Xu, "Discontinuous and continuous Galerkin methods for compressible singlephase and two-phase flow in fractured porous media," Advances in Water Resources, vol. 156, article 104039, 2021.

[51] T. Ma, J. Rutqvist, C. M. Oldenburg, W. Liu, and J. Chen, "Fully coupled two-phase flow and poromechanics modeling of coalbed methane recovery: impact of geomechanics on production rate," Journal of Natural Gas Science and Engineering, vol. 45, pp. 474-486, 2017.

[52] Z. Wei and D. Zhang, "A fully coupled multiphase multicomponent flow and geomechanics model for enhanced coalbedmethane recovery and CO2 storage," SPE Journal, vol. 18, no. 3, pp. 448-467, 2013.

[53] J. G. Wang and Y. Peng, "Numerical modeling for the combined effects of two-phase flow, deformation, gas diffusion and $\mathrm{CO}_{2}$ sorption on caprock sealing efficiency," Journal of Geochemical Exploration, vol. 144, pp. 154-167, 2014.

[54] W. Yuan, Z. Pan, X. Li et al., "Experimental study and modelling of methane adsorption and diffusion in shale," Fuel, vol. 117, pp. 509-519, 2014.

[55] L. Wang, M. Bornert, E. Héripré, S. Chanchole, A. Pouya, and B. Halphen, "Microscale insight into the influence of humidity on the mechanical behavior of mudstones," Journal of Geophysical Research: Solid Earth, vol. 120, no. 5, pp. 3173-3186, 2015.

[56] J. G. Wang, A. Kabir, J. Liu, and Z. Chen, "Effects of non-Darcy flow on the performance of coal seam gas wells," International Journal of Coal Geology, vol. 93, pp. 62-74, 2012. 
[57] R. Aringhieri, "Nanoporosity characteristics of some natural clay minerals and soils," Clays and Clay Minerals, vol. 52, no. 6, pp. 700-704, 2004.

[58] W. Shen, X. Li, T. Ma, J. Cai, X. Lu, and S. Zhou, "High-pressure methane adsorption behavior on deep shales: experiments and modeling," Physics of Fluids, vol. 33, no. 6, article 063103, 2021.

[59] J. Li, X. Li, X. Wang et al., "Water distribution characteristic and effect on methane adsorption capacity in shale clay," International Journal of Coal Geology, vol. 159, pp. 135-154, 2016.

[60] J. Zhang, B. Zhang, S. Xu, Q. Feng, X. Zhang, and D. Elsworth, "Interpretation of gas/water relative permeability of coal using the hybrid Bayesian-assisted history matching: new insights," Energies, vol. 14, no. 3, p. 626, 2021.

[61] R. H. Brooks and A. T. Corey, "Hydraulic properties of porous media and their relation to drainage design," Transactions of the ASAE, vol. 7, no. 1, pp. 0026-0028, 1964.

[62] M. T. Van Genuchten, "A closed-form equation for predicting the hydraulic conductivity of unsaturated soils," Soil Science Society of America Journal, vol. 44, no. 5, pp. 892-898, 1980.

[63] M. Leverett, "Capillary behavior in porous solids," Transactions of the AIME, vol. 142, no. 1, pp. 152-169, 1941.

[64] D. S. Lee, J. D. Herman, D. Elsworth, H. T. Kim, and H. S. Lee, "A critical evaluation of unconventional gas recovery from the Marcellus Shale, northeastern United States," KSCE Journal of Civil Engineering, vol. 15, no. 4, pp. 679-687, 2011.

[65] B. R. Meyer, L. W. Bazan, R. H. Jacot, and M. G. Lattibeaudiere, "Optimization of multiple transverse hydraulic fractures in horizontal wellbores," in SPE Unconventional Gas Conference, Pennsylvania, USA, 2010.

[66] W. Yu and K. Sepehrnoori, "Simulation of gas desorption and geomechanics effects for unconventional gas reservoirs," Fuel, vol. 116, pp. 455-464, 2014.

[67] W. Yu, T. T. Zhang, S. du, and K. Sepehrnoori, "Numerical study of the effect of uneven proppant distribution between multiple fractures on shale gas well performance," Fuel, vol. 142, pp. 189-198, 2015.

[68] Y. Tan, Z. Pan, J. Liu, X.-T. Feng, and L. D. Connell, "Laboratory study of proppant on shale fracture permeability and compressibility," Fuel, vol. 222, pp. 83-97, 2018. 